\title{
Shear crack pattern identification in concrete elements via distributed optical fiber grid.
}

\author{
Gerardo Rodríguez*, Joan R. Casas** \& Sergi Villalba*** \\ *Institute of Engineering, National Autonomous University of Mexico UNAM. Mexico \\ City, Mexico \\ **Technical University of Catalonia, UPC-BarcelonaTech. Department of Civil and \\ Environmental Engineering. Barcelona, Spain \\ *** Technical University of Catalonia, UPC-BarcelonaTech. Department of Project \\ and Construction, Terrassa, Spain
}

* Corresponding author: Tel.: +556233600 ext 8417 email: grog@ pumas.ii.unam.mx 
ABSTRACT

An experimental methodology to obtain the shear cracking pattern in concrete elements is presented. The method is based on the use of Distributed Optical Fiber Sensors (DOFS) connected to an Optical Backscattered Reflectometer (OBR). Using this OBR system and a 2D grid conformed by one or two DOFS, the crack patterns of three partially pre-stressed concrete (PPC) beams subjected experimentally to shear failure, were obtained for increasing level of load. The 2D distributed fiber optic sensoring mesh was formed by attaching the fiber to the shear span of each beam using an epoxy adhesive. The importance of a correct DOFS attaching procedure to the concrete surface to obtain accurate results is described, and the principal advantages of DOFS to complement the use of discrete sensors in concrete experimental shear tests are shown. The proposed technique is a powerful tool to be implemented in the structural health monitoring in shear of concrete structures, where the variable inclined cracks are difficult to monitor by other experimental techniques using discrete sensors.

Keywords: Distributed Optical Fiber Sensor (DOFS), Optical Backscattered Reflectometer (OBR), concrete structures, experimental methodologies, shear crack pattern.

\section{Introduction}

In concrete beams subjected to shear, cracks become inclined with an angle respect to the axis of the structural element that is difficult to predict. For this reason, the mechanism of diagonal cracking in concrete beams is more complex than cracking due to axial force or bending, because a diagonal crack is not perpendicular to the vertical and transversal reinforcement. Compared to the case of bending, where the cracks appear orthogonally to the beam axis, in case of shear action, the inclination of the cracking pattern is an additional unknown to the crack width.

Additionally, most of the existing guidelines and experimental studies related to crack control in concrete structures have been originally developed for tensile and flexural cracks cases. Due to the different mechanisms leading to shear cracking, these procedures 
can not be applied to obtain shear crack patterns directly. In concrete elements subject to shear, failure mechanism is characterized by the occurrence of inclined cracks either before or after a flexural crack forms and by the shear sliding displacements along the cracks.

Significant efforts have been developed to clarify and understand the problem of detection and locate shear cracks in concrete structures. Experimental approaches have been performed (Bazant et al 1983, Borosnyói et al 2005). In these tests, the experimental data have been obtained through procedures using different local sensors, which generally produce a discrete value of the studied structural parameters. Because the shear cracking pattern in concrete structures is a $2 \mathrm{D}$ problem, a great number of these discrete sensors are required to obtain enough data to study the principal parameters that describe the shear behaviour. For this reason, it is a common practice that the experimental shear tests preparation are more time-consuming. Also, during and after the test, several manual and observational activities have to be performed such as tracing the cracks pattern with a marking pen, or measuring the cracks width progression by using visual techniques. It is important to consider these implications, since several measuring errors could be obtained in all of these activities.

New measuring methodologies based on the use of distributed optical fiber sensors (DOFS) have been proposed (Villalba and Casas 2013, Rodríguez et al 2015a,b). One of the principal advantages over traditional measuring techniques, is the easy installation of the sensors, which basically consists on bonding an optical fiber to a host surface. In some cases the bonding surface corresponding to an existing element, whereas in other cases the sensors can be embedded into the concrete matrix by bonding them to the reinforcing bars at the time of construction (Davis et al. 2016, Davis et al. 2017, Barrias et al. 2018d). 
A comprehensive summary of the civil engineering applications of DOFS can be found in Rodriguez et al. 2015c and Barrias et al. 2016. The DOFS is able to measure strain and/or temperature along the whole fiber with a high spatial resolution by using the Rayleigh backscattering light. This monitoring system uses swept-wavelength coherent interferometry to measure the Rayleigh backscattered as a function of position in the optical fiber (LUNA 2013). An external stimulus (like a strain or temperature change) causes temporal and spectral shifts in the local Rayleigh backscatter pattern. These temporal and spectral shifts can be measured and scaled to give a distributed temperature or strain measurement (Samiec 2012).

Among these methodologies, the use of the optical backscattered reflectometer (OBR) system highlights, since the high spatial resolution and accuracy are its main characteristics. The optical fiber cable connected to an OBR system, becomes a DOFS with thousands of measuring points, (Villalba 2010). This paper is based on some previous experiences by the authors where the OBR system was used in the detection, location and assessment of the crack width in concrete structures subjected to bending (Villalba 2010, Villaba and Casas 2013, Rodríguez et al 2015a). Also, it is an extension of a previous paper (Rodríguez et al 2015b and Rodríguez et al, 2016) in which, preliminary shear experimental data in two PPC concrete beams was presented.

\section{Monitoring of shear crack pattern in concrete elements}

In order to fully characterize the shear crack pattern of a concrete element, it is important to determine the crack evolution since the beginning of its detection and location. To do this, the following parameters are established as shown in the Fig. 1: an angle $\theta$ is defined between the horizontal axis and the shear crack inclination trajectory. The shear crack 
width $w_{d}$ is obtained using its two components $w_{m x}$ and $w_{m y}$ with respect to classic orthogonal axes. At the same time, a sliding displacement $s_{d}$ along the crack is produced by the shear displacements (see Fig. 1).

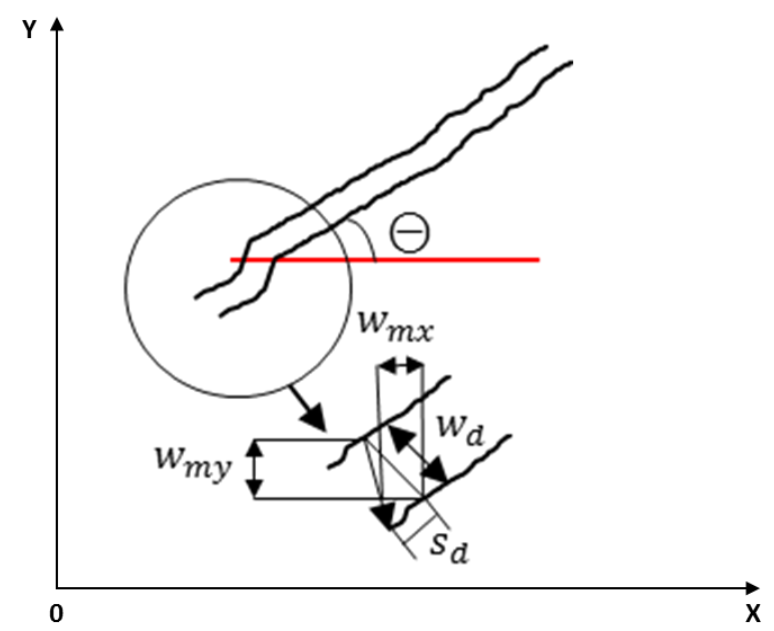

Fig. 1. Schematic representation of shear crack pattern in a concrete element

Due to the complexity of the response to shear, deploying several types of sensors to cover the possible cracked zone is a common practice during a shear test. For this reason, different types of monitoring set-ups had been established to obtain crack patterns during a shear test. One example is shown in Fig. 2, based on the use of strain gauges to conform strain rosettes
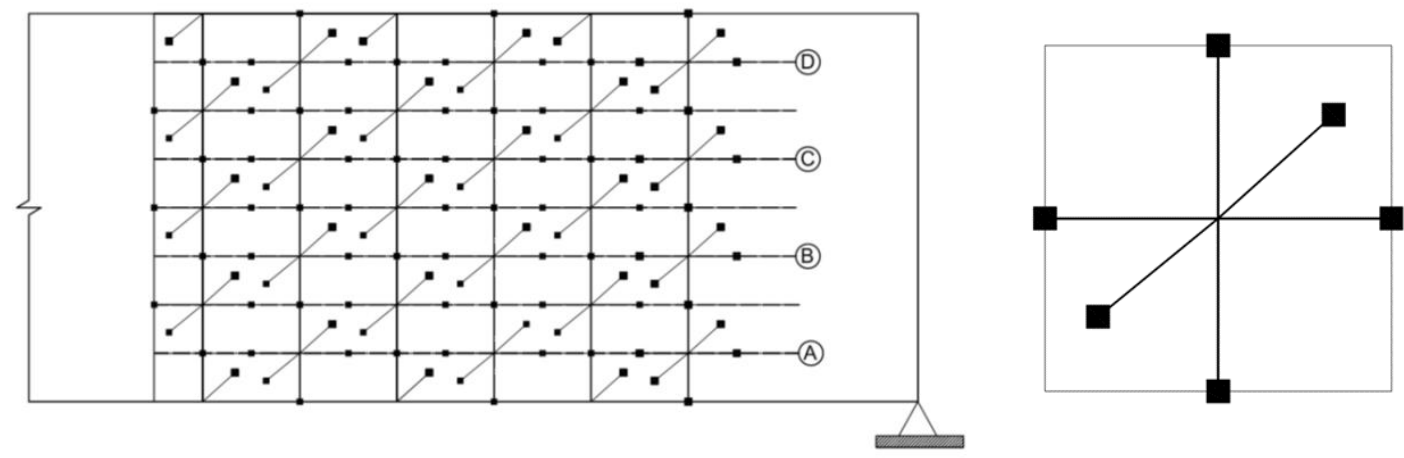

Fig. 2. Strain rosettes conformed by strain gauges in a concrete beam for a shear lab test. 
Other example (Fig. 3) is the use of strain rosettes conformed by linear variable differential transducers (LVDT) or potentiometers. Also it is common to use discrete strain gauges distributed on the surface and also embedded and attached to the horizontal and vertical reinforcement bars (Stoerzel and Randal, 2015).
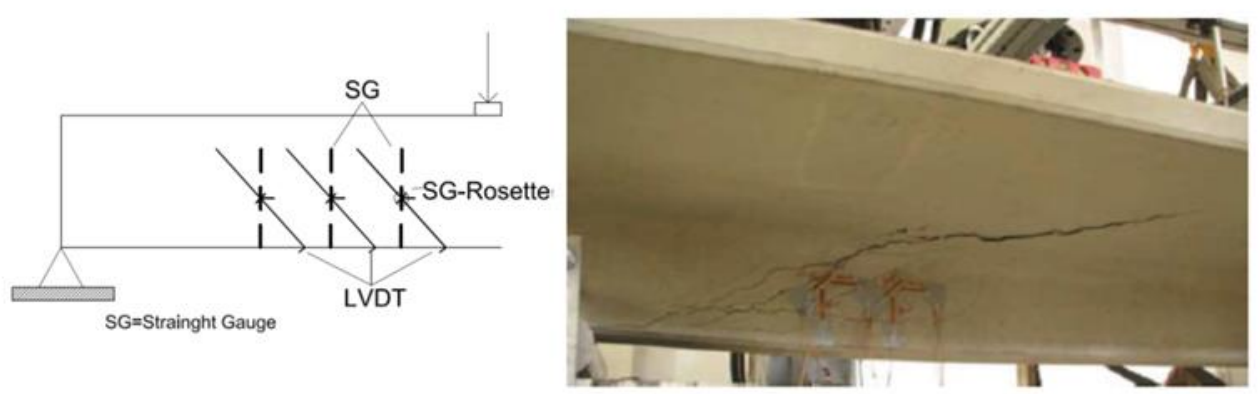

Fig. 3. Strain rosettes conformed by LVDT's and embedded strain gauges in a T-concrete beam for a shear lab test (Stoerzel and Randal, 2015).

Although discrete sensors as strain gauges or LVDT's provide useful information about structural behavior, these sensors are limited to detect and valuate cracks width in concrete beams. Usually to cover this limitation, a great number of discrete sensors are deployed to measure in different points and to obtain the complex shear crack pattern.

Due to the explained limitations and based on the promising results obtained in the crack pattern identification of concrete elements in bending by using DOFS and an OBR system (Rodríguez et al., 2014), a novel methodology is proposed for the assessment of shear crack patterns in concrete elements. 


\section{Proposed Methodology to obtain the shear crack pattern}

Based on the case of crack pattern identification of concrete elements in bending (Villalba 2010, Villaba and Casas 2013, Rodríguez et al 2014, Rodríguez et al 2015a, Rodríguez. et al 2015b, Rodríguez et al 2016), the proposed method for the shear case is based on the analysis of the distribution of strains along a DOFS. However, due to the unknown inclination of the shear cracks, to detect and locate the crack, a monitoring method must be established to determine the strain distribution in at least two perpendicular directions. Thus, an arrangement with one or two DOFS is proposed to form a grid within the area in which these cracks are expected to occur (zone of maximum shear within the element). A schematic representation of this mesh is shown in Fig 4. As in the case of bending, a peak in the strain profile measured by the fiber will appear in the location where a crack will form. This will be used to detect and locate the crack. The strain profiles in two orthogonal directions will serve to obtain the inclination of the crack.

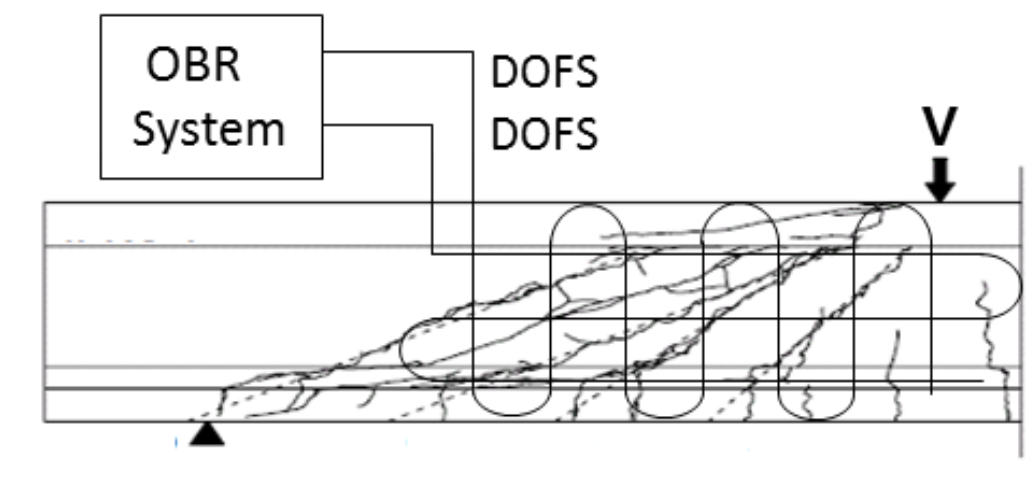

Fig.4. Rectangular 2D mesh formed by the DOFS for the characterization of shear cracking.

To check the feasibility and reliability of the proposed method, a set of tests were carried out in 3 partial pre-stressed concrete (PPC) beams as explained in the following sections. 


\section{Experimental Program}

Laboratory tests on three partially pre-stressed concrete beams of $8 \mathrm{~m}$ in length were performed. The three beams were also instrumented with standard discrete sensors to compare the results from the fiber optic sensors (Bairán, et al., 2014, Celada, 2015).

\section{Specimens}

The cross-section, dimensions and the arrangement of the transversal and longitudinal reinforcing steel and post-tensioning tendon are presented in Figs. 5 and 6 and in Table 1. The main differences in the beams are the amount of pre-stressing and the shear reinforcement. The diameter of stirrups is the same $(6 \mathrm{~mm})$ but with different spacing (see Table 1). In Table 1, $\sigma \mathrm{p}$ is the steel stress at jacking.The beams are post-tensioned by different number of strands within the duct. The layout of the post-tensioning is inclined in one part of the beam and straight in the rest.
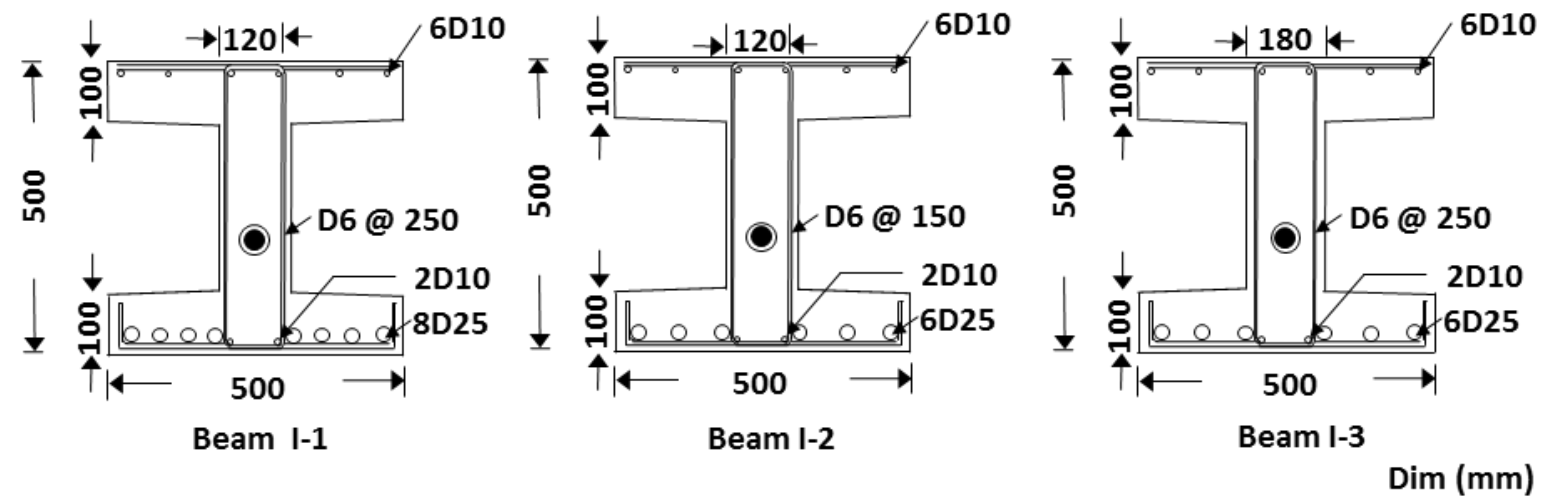

Fig. 5. Cross-section of I-beams 
Table 1. Main characteristics of the beams

\begin{tabular}{|c|c|c|c|c|c|c|c|}
\hline \multirow{2}{*}{ Beam } & \multirow{2}{*}{$\begin{array}{c}\text { web } \\
\text { thickness } \\
(\mathrm{mm})\end{array}$} & \multicolumn{2}{|c|}{ Reinforcing steel } & \multicolumn{3}{|c|}{ Prestressing steel } & \multirow{2}{*}{$\begin{array}{c}\text { Stirrups } \\
\text { spacing } \\
(\mathrm{mm})\end{array}$} \\
\hline & & Upper & Botom & Strands & area $\left(\mathrm{mm}^{2}\right)$ & $\sigma p(\mathrm{Mpa})$ & \\
\hline $\mathrm{I}-1$ & 120 & 6 D10 & 8 D25+2 D10 & 2 & 300 & 1312 & 250 \\
\hline $\mathrm{I}-2$ & 120 & $6 \mathrm{D} 10$ & $6 \mathrm{D} 25+2 \mathrm{D} 10$ & 2 & 300 & 1312 & 150 \\
\hline $\mathrm{I}-3$ & 180 & $6 \mathrm{D} 10$ & 6 D25+2 D10 & 4 & 600 & 1303 & 250 \\
\hline
\end{tabular}
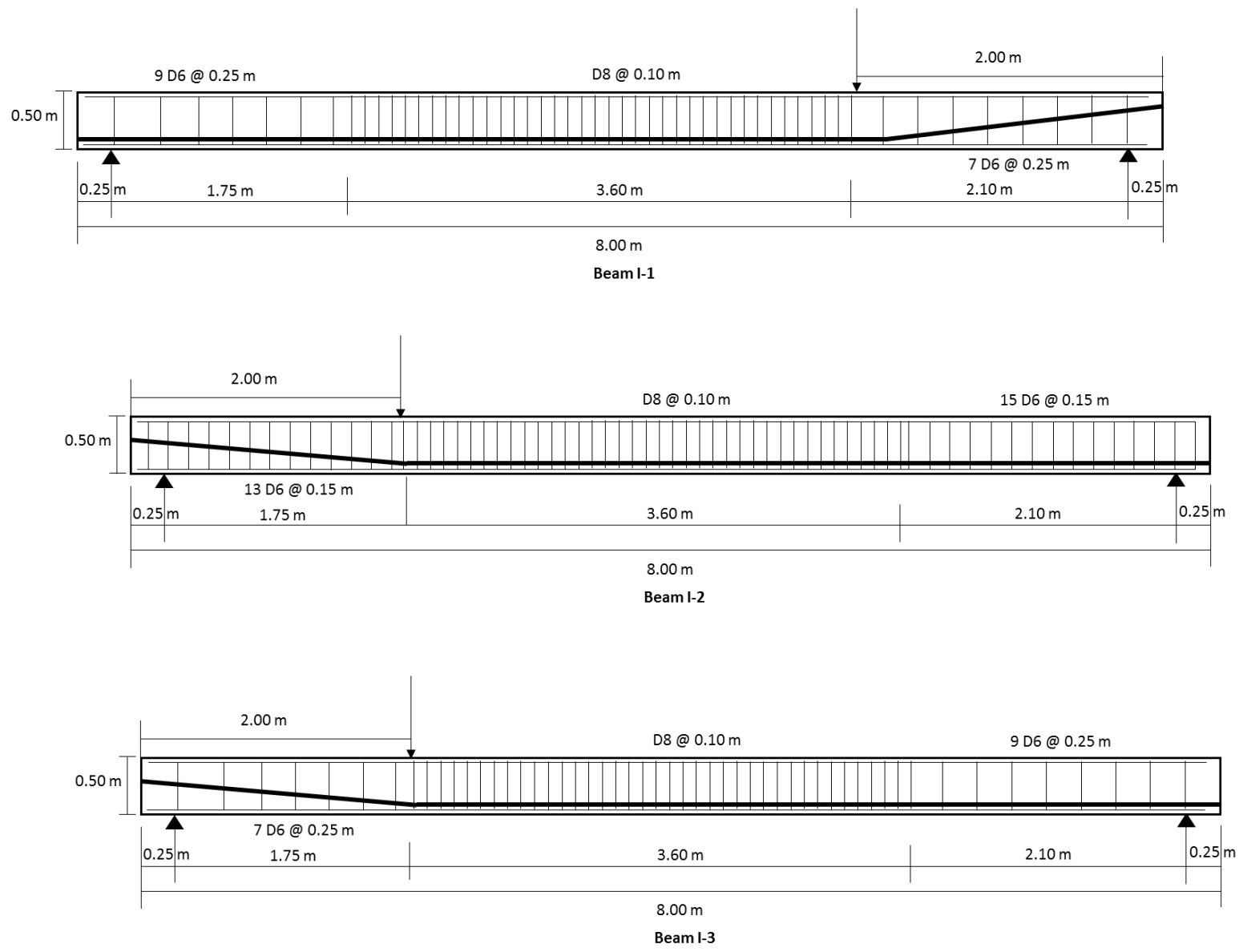

Fig. 6. Definition of reinforcing and prestressing steel, beams dimensions and details. 
The mechanical properties of the concrete are presented in Table 2, where $f_{\mathrm{cm}}$ is the concrete compressive strength, $\mathrm{f}_{\mathrm{ct}}$ is the concrete tensile strength and $\mathrm{E}$ is the concrete elasticity modulus. The values of $\varepsilon_{\mathrm{fct}}$ are the maximum tensile strain, which is a threshold value. When this value is reached in the concrete, the crack appears.

Table 2. Concrete mechanical properties

\begin{tabular}{|c|c|c|c|c|}
\hline Specimen & $\begin{array}{c}\mathrm{f}_{\mathrm{cm}} \\
(\mathrm{Mpa})\end{array}$ & $\begin{array}{c}\mathrm{f}_{\mathrm{ct}} \\
(\mathrm{Mpa})\end{array}$ & $\begin{array}{c}\mathrm{E} \\
(\mathrm{Mpa})\end{array}$ & $\begin{array}{c}\varepsilon_{\mathrm{fct}} \\
\mu \varepsilon\end{array}$ \\
\hline $\mathrm{I}-1$ & 325 & 4.6 & 36440 & 126 \\
$\mathrm{I}-2$ & 293.5 & 4.15 & 27264 & 152 \\
$\mathrm{I}-3$ & 414.6 & 5.86 & 34261 & 171 \\
\hline
\end{tabular}

\section{Test set-up}

To detect and locate the cracks, in each of the three beams a DOFS arrangement connected to the OBR system was proposed forming a 2D grid in the shear zone. These grids were formed in the web of the beam with a DOFS of $10 \mathrm{~m}$ and another of $5 \mathrm{~m}$ in length, in the beam I-1. Subsequently, in the two remaining beams I-2 and I-3, the 2D grid was formed only with a DOFS of $10 \mathrm{~m}$ in length.

Although in general similar meshes were formed, in each of the tested beams there were differences due to their placement. From Figs. 6 to 8, each of these configurations is shown. In these 2D configurations, the horizontal grid sections were nominated as A, B, $\mathrm{C}, \mathrm{D}, \mathrm{E}$ and $\mathrm{F}$. The vertical sections were nominated using the numbers 1 to 10 .

To have a comparative reference of the results obtained with the OBR system, a standard instrumentation consisting on several strain gauges is deployed in the reinforcing and prestressing steel to measure their strain in selected locations. . A complete and detailed 
description of this instrumentation is available in Celada, 2015. From the large amount of deployed sensors, only the results relevant for this research will be considered in the following.

The data obtained in the strain gauges embedded in the passive steel placed in the shear area is considered. In Figs. 6 to 8 are located the number of strain gauges that were embedded in the stirrups in each beam.

The position of each strain gauge in the stirrups is indicated and they are identified as G. The stirrups were numbered from S1 to S6, and it can be seen that in general more than one strain gauge was placed along the height of each stirrup (h1, h2, h3 and h4). The objective is to measure the variation of strain along the length of the stirrup.

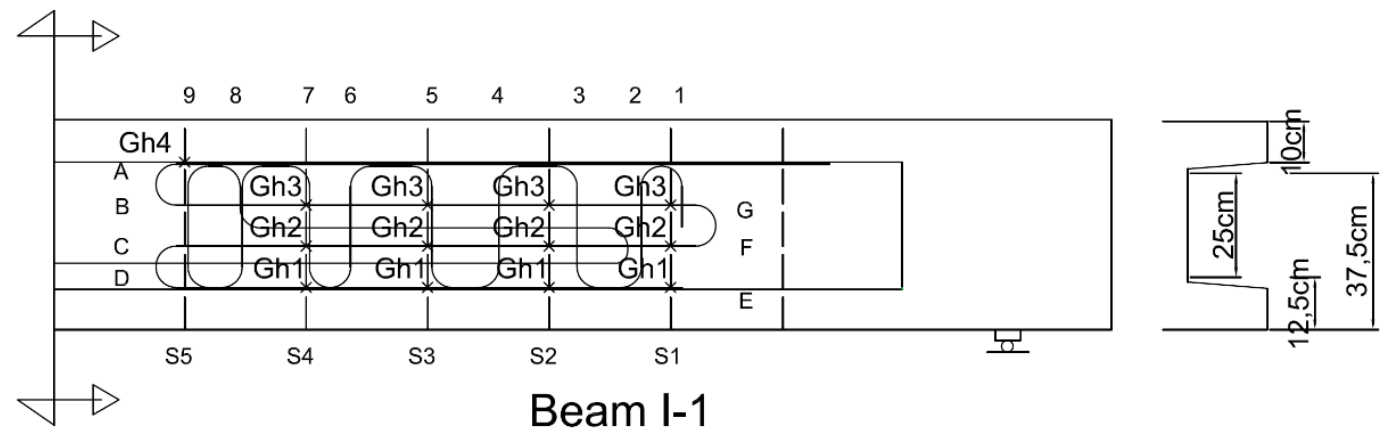

Fig. 6. SFOD arrangement for the I-1 beam shear test.

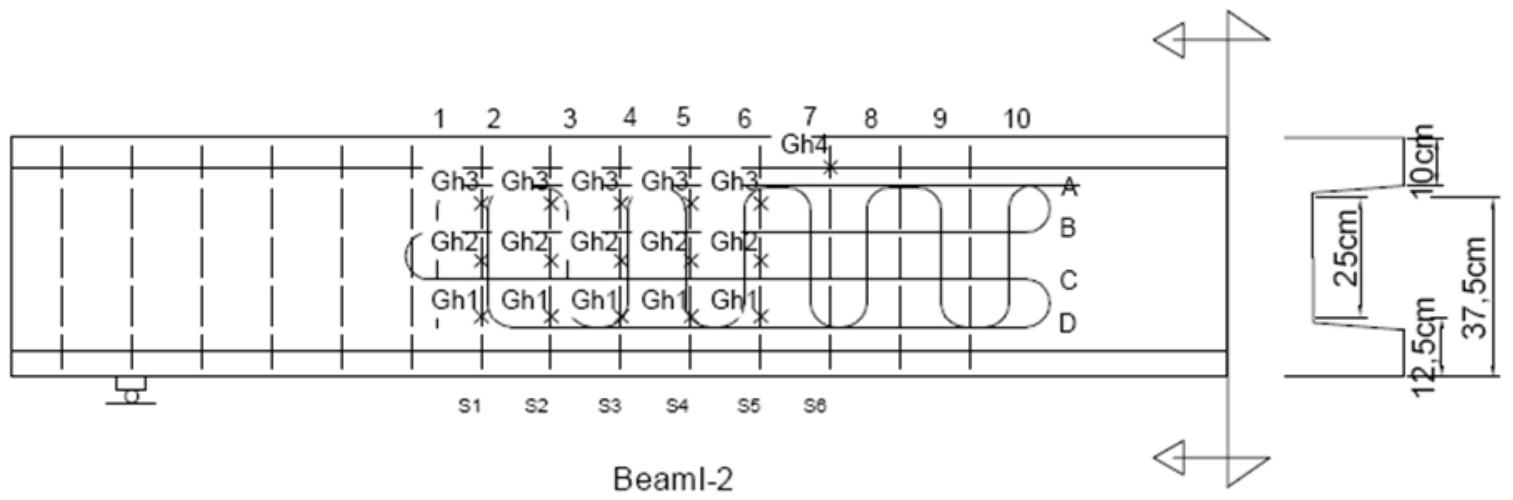

Fig. 7. SFOD arrangement for the I-2 beam shear test. 


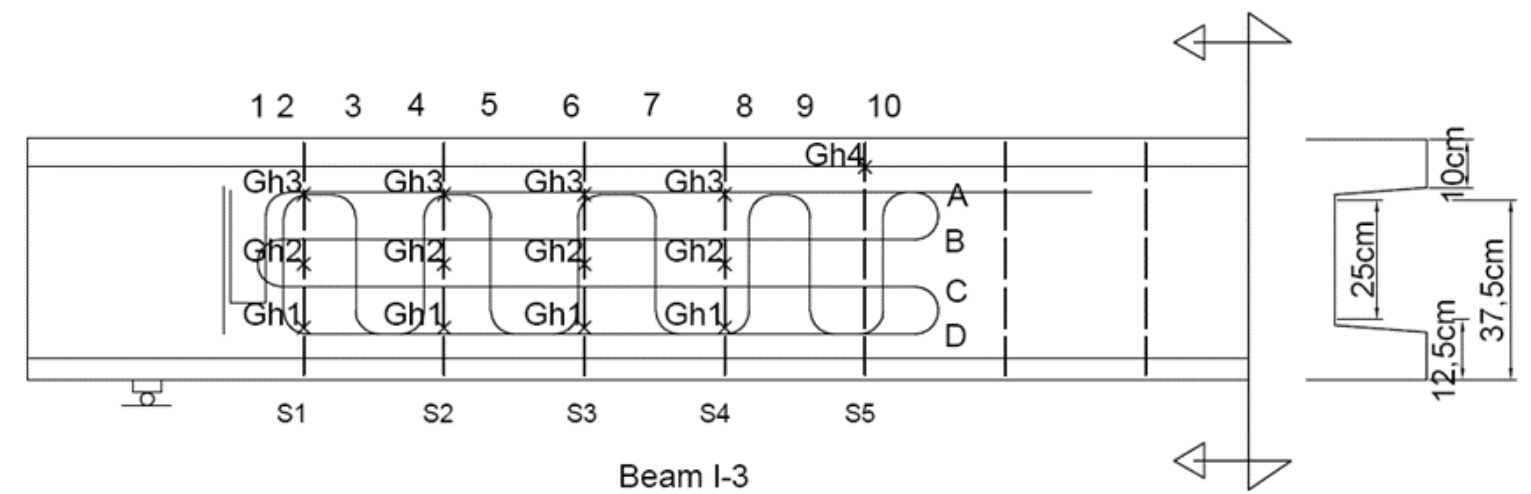

Fig. 8. SFOD arrangement for the I-3 beam shear test.

\section{DOFS bonding procedure}

Only basic guidance on the bonding of the DFOS was supplied by the supplier (LUNA, 2017). This was focused in bonding the sensors onto a relatively smooth metallic or composite surfaces and in short lengths. However, based on the previous experiences by the authors in deploying this type of sensors in concrete structures, the following protocol was followed up (Villalba and Casas 2013, Casas et al. 2014) as presented in figures 10 to 13 .
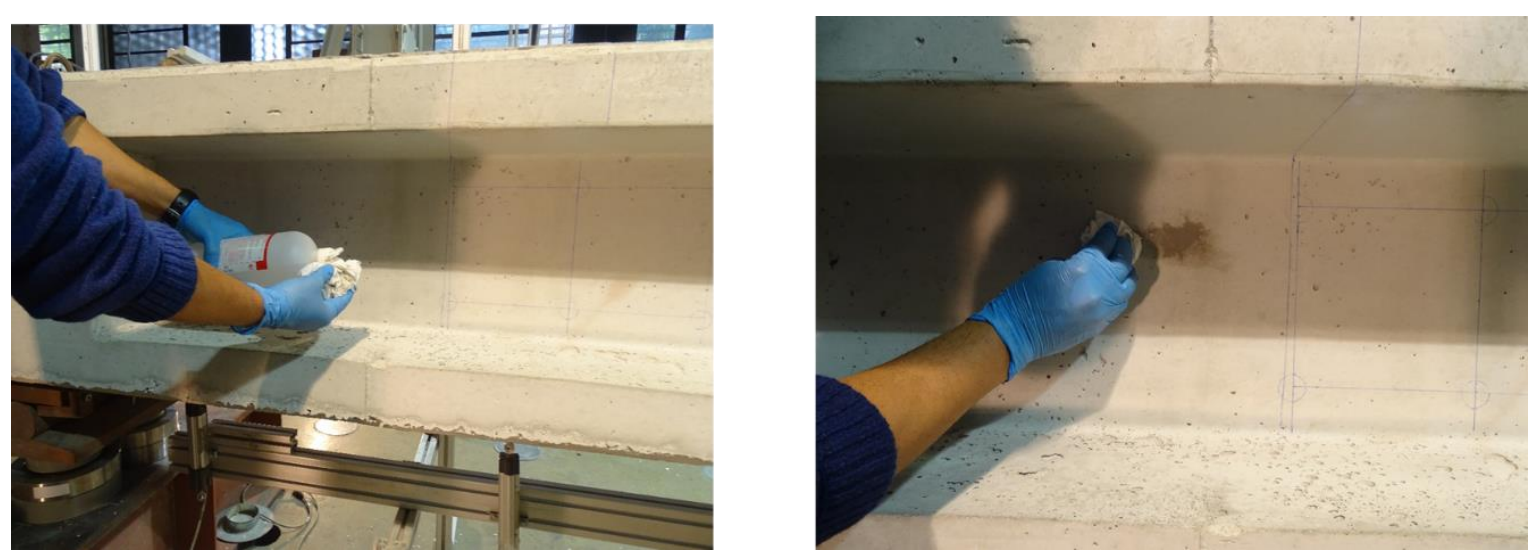

Fig. 10. Cleaning process of the concrete surface 
Fig. 10 shows the cleaning process with alcohol of the concrete surface, with the aim to eliminate the presence of dust and impurities that may affect the bonding of the fiber to the surface. After that, the selected surfaces were prepared to develop suitable bond areas as shown in Fig. 11. The proposed DOFS path is marked with discrete adhesive points before lying the fiber (Figure 12 left).
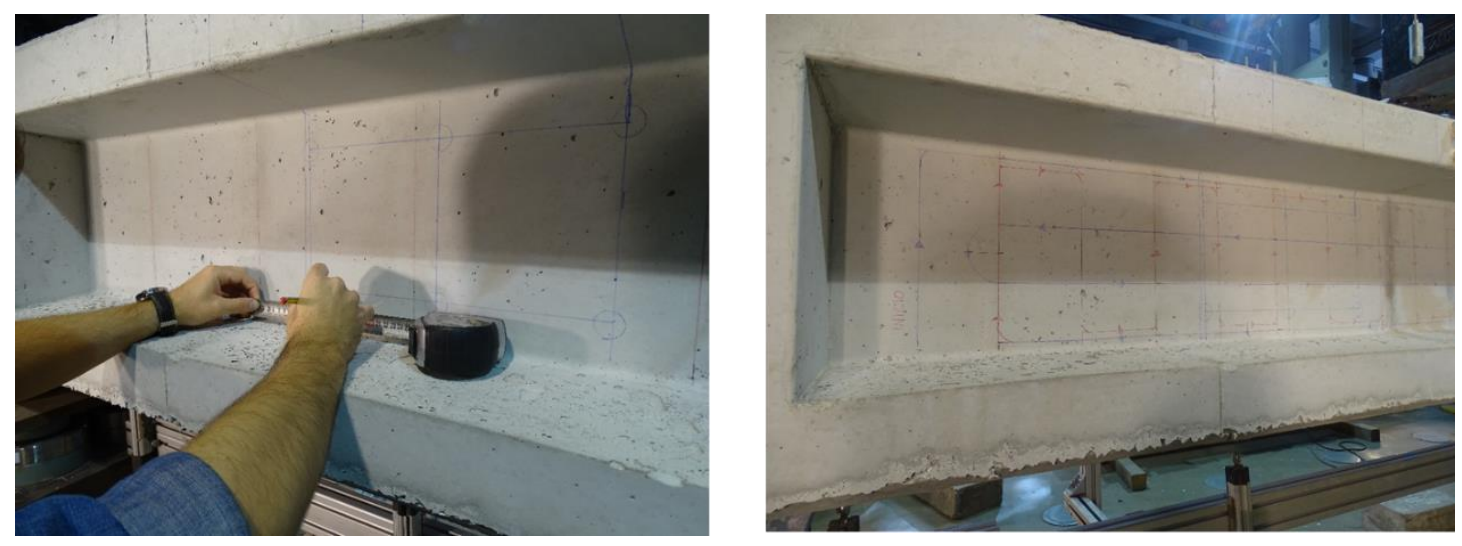

Fig. 11. Stroke path of the fiber to form a 2D mesh in the beam cutting area

After this, the final step is to apply the bonding agent and cure it into the monitored surface (figure 12 right). A commercial glue as epoxy or cyanoacrylate could be applied. Some experiences (Hoult et al 2014, Regier 2013, Barrias et al. 2018b,c) have shown that in the laboratory environment, the installation with epoxy produces better results than using cyanoacrylate adhesives in concrete surfaces.

According to that, a commercial bicomponent epoxy adhesive (Araldit) was applied to the bond area. A small brush was used to cover the DOFS with epoxy avoiding applying adhesive in excess (Rodriguez et al 2015, Regier and Hoult 2014) as shown in Fig. 12. The bond thickness (amount of epoxy between the fiber and the surface) should be minimized to ensure that the fiber is truly resting on the surface of the monitored structure 
as shown in the Fig.13. (LUNA, 2017). Finally, a view of the installed optical fiber is shown in Fig. 14.
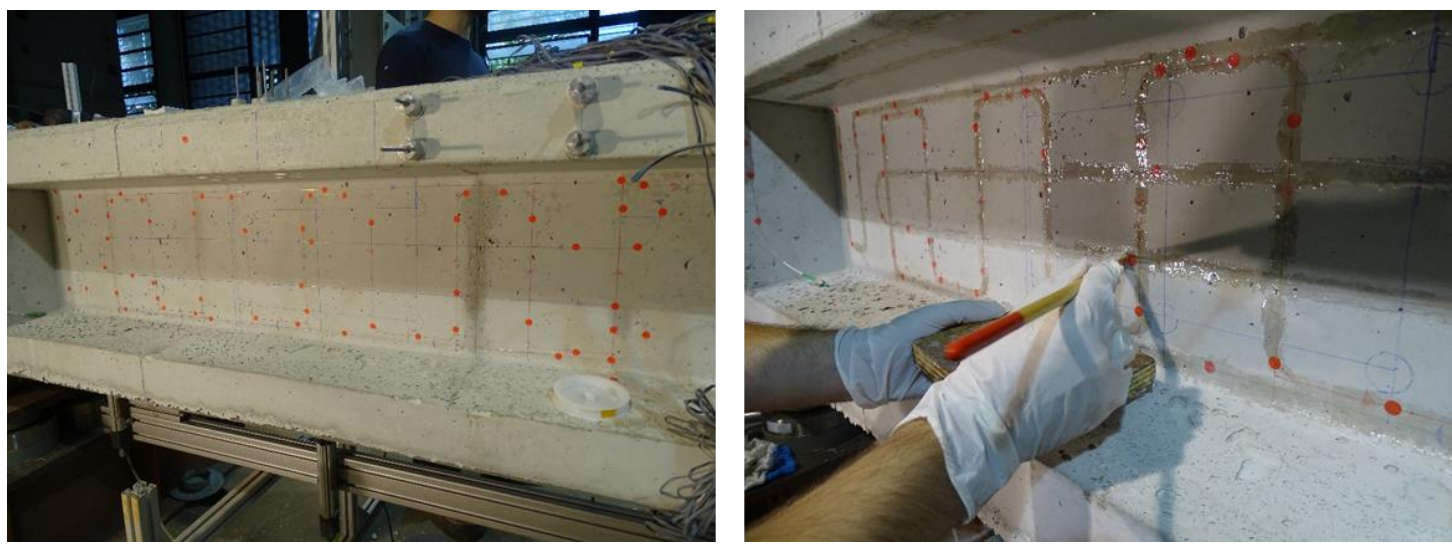

Fig. 12. Presentation and bonding of the optical fiber to the web of the concrete beam.

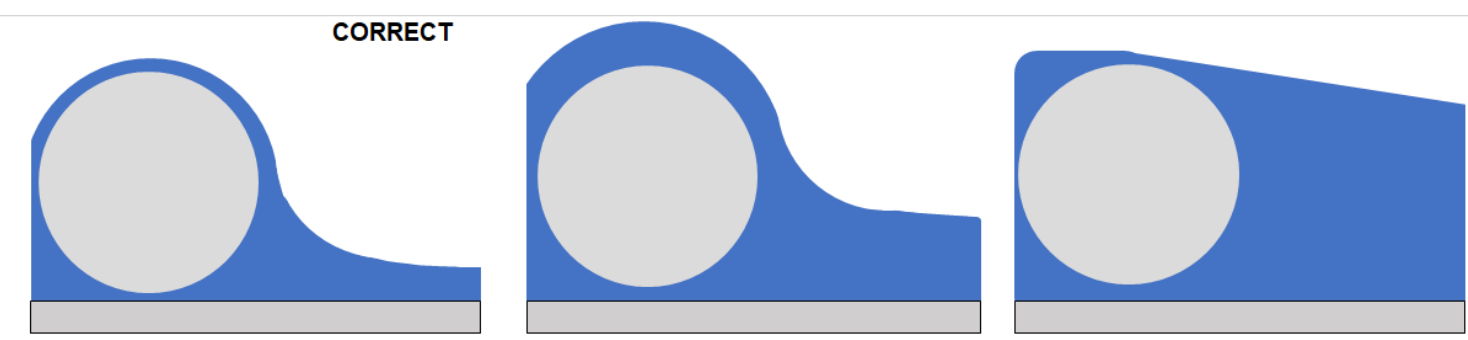

Ensure a thin bold line enough epoxy is applied around the fiber

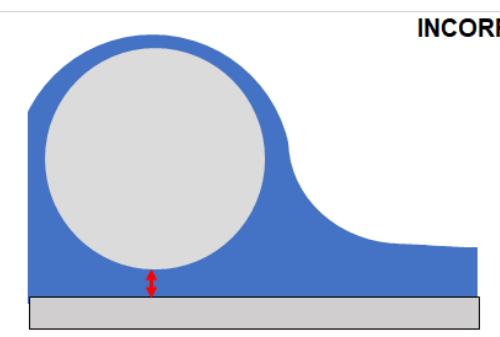

Bond line too thick

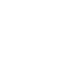




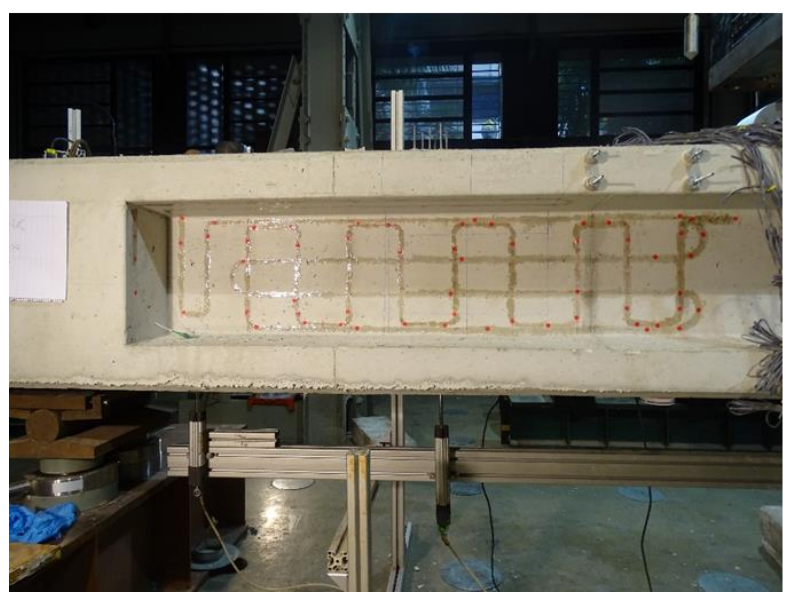

Fig.14. View of installed optical fiber

The type of sensor used (LUNA, 2012), is a silica (glass) single mode fiber polyimide coated with an overall diameter of 155 microns. The diameter of the cladding is 125 microns, which makes the coating thickness around 15 microns. The core diameter is around 5 microns. The polyimide protects the sensor from scratches and environmental attack. The principal reason to use a practically nude fiber, is to transfer any strain or temperature variation from the host material to the fiber core in the best way, without any other material between them as in the case of a packaged fiber (Barrias et al 2018a). In general the DOFS is strong in tension but weak in shear, therefore care needs to be taken in the DOFS during deployment to avoid rupture. To prevent this, is recommended to unwind carefully the DOFS from the spool and to attach down a maximum of $1 \mathrm{~m}$ of the DOFS only using small adhesive dots to hold the DOFS in the planned route without any previous layer of adhesive on the surface (Barrias et al 2018a). 


\section{Measurement system}

OBR system uses swept-wavelength coherent interferometry to measure the Rayleigh backscattered as a function of position in the optical fiber. An external stimulus (like a strain or temperature change) causes temporal and spectral shifts in the local Rayleigh backscatter pattern. These temporal and spectral shifts can be measured and scaled to give a distributed temperature or strain measurement (Samiec 2012). This process is shown in Fig. 15. More information on the system characteristics is available in Casas et al. 2014 and Rodríguez et al. 2015.

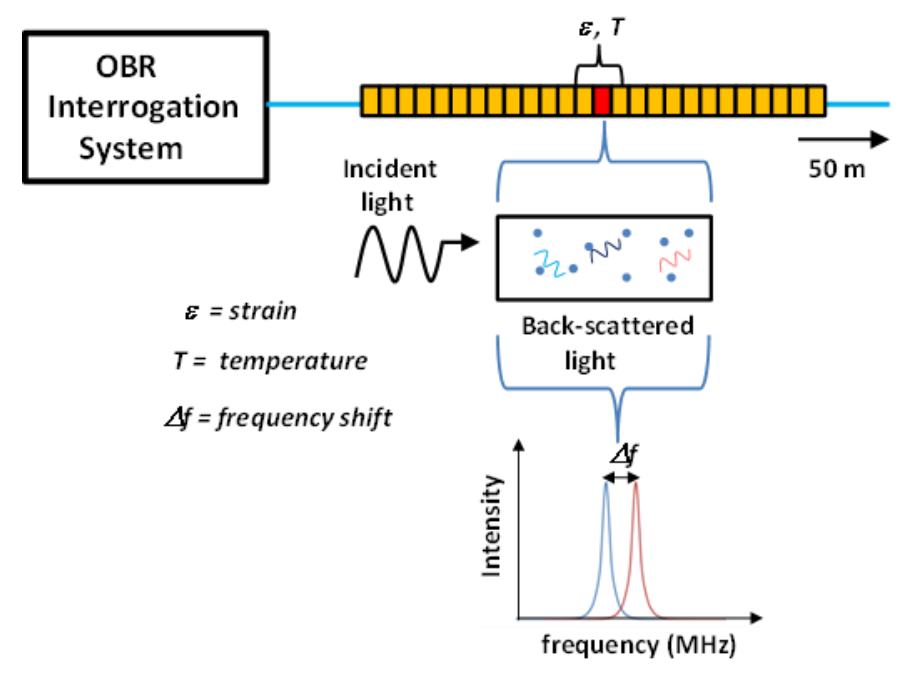

Fig. 15. OBR measurement process (Rodriguez et al, 2015)

Continuous strain data with high spatial resolution and great accuracy are the main advantages of OBR. This structural monitoring technique enables distributed strain measurements with millimetre-spatial resolution. Several experiences have demonstrated the feasibility of using this technique either in the structural monitoring of existing concrete structures (Barrias et al. 2018a) and in laboratory tests (Villalba et al 2012). 
The main components of the OBR system are:

- Optical Ditributed System Interrogator

- 8 channels Fiber Optic Switch

- A optical wire connection

- DOFS with FC/APC terminal and 5, 10 and $20 \mathrm{~m}$ of length.

- Lap Top

The few components of OBR system, results in an easy and quick installation, makes this system a very practical tool for structural monitoring in field and laboratory. An OBR general view is shown in Fig. 16.

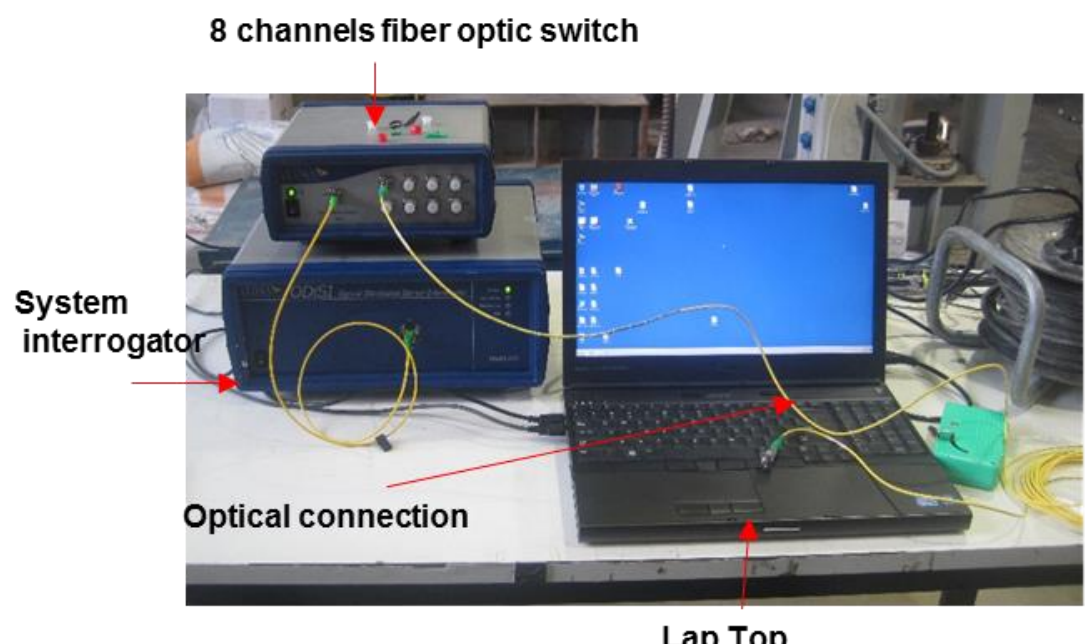

Lap Top

Fig. 16. OBR system components

The main OBR system technical specifications of the equipment used in the tests are shown in Table 3.

Table 3. OBR system main charactheristics

\begin{tabular}{|l|c|}
\hline \multicolumn{1}{|c|}{ Parameter } & Specification \\
\hline Maximum Sensing Length & $50 \mathrm{~m}$ \\
\hline Minimum Sensing Length & $0.5 \mathrm{~mm}$ \\
\hline Acquisition Rate & $2.5 \mathrm{~Hz}$ \\
\hline Strain Range & $(+/-) 15000 \mu \varepsilon$ \\
\hline Temperature & $\left(-50 \mathrm{a} 300^{\circ} \mathrm{C}\right)$ \\
\hline Dimensions & $(36 \times 32 \times 17 \mathrm{~cm})$ \\
\hline
\end{tabular}




\section{Test execution and results}

The beams were tested under static load, applied gradually and with six loading and unloading cycles. The applied force was controlled by displacement of 1 and $2 \mathrm{~mm} / \mathrm{min}$, until the three concrete beams failed. The loading sequences are shown in Figs. 17, 18 and 19 using a stitch line. Also in these figures, the load level associated with DOFS failure is indicated with a point.

\section{Beam I-1}

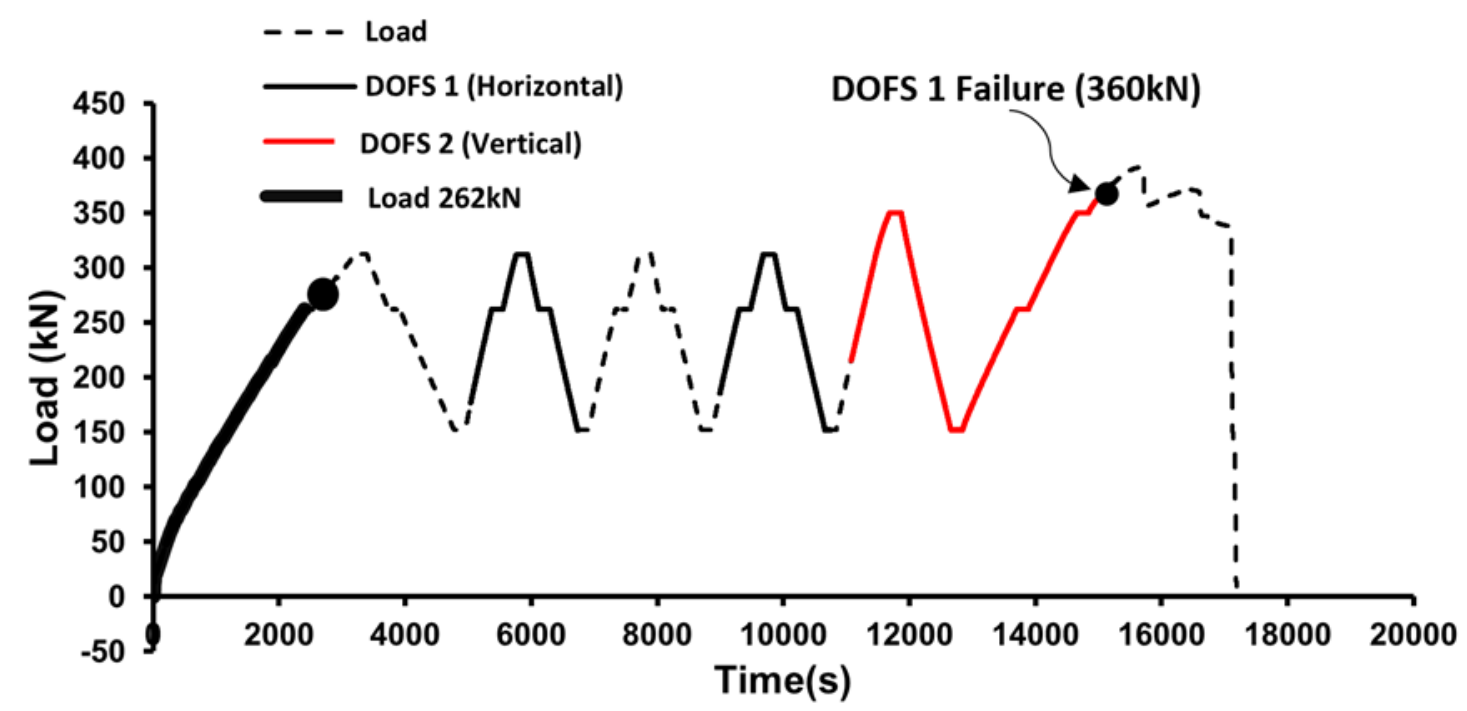

Fig. 17. Load history of beam I-1, part of the test record with DOFS and fiber break point 


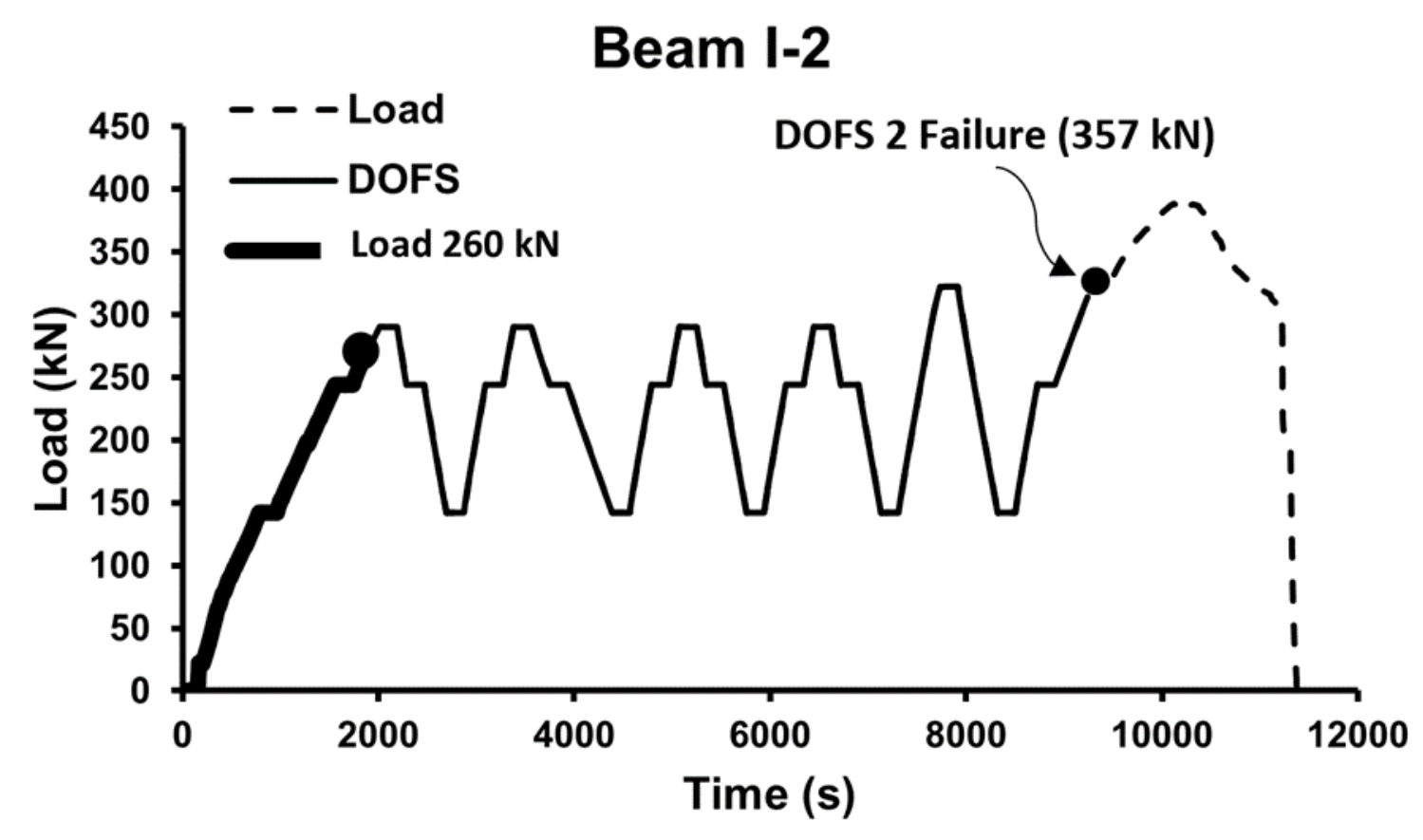

Fig. 18. Load history of beam I-2, part of the test record with DOFS and fiber break point 


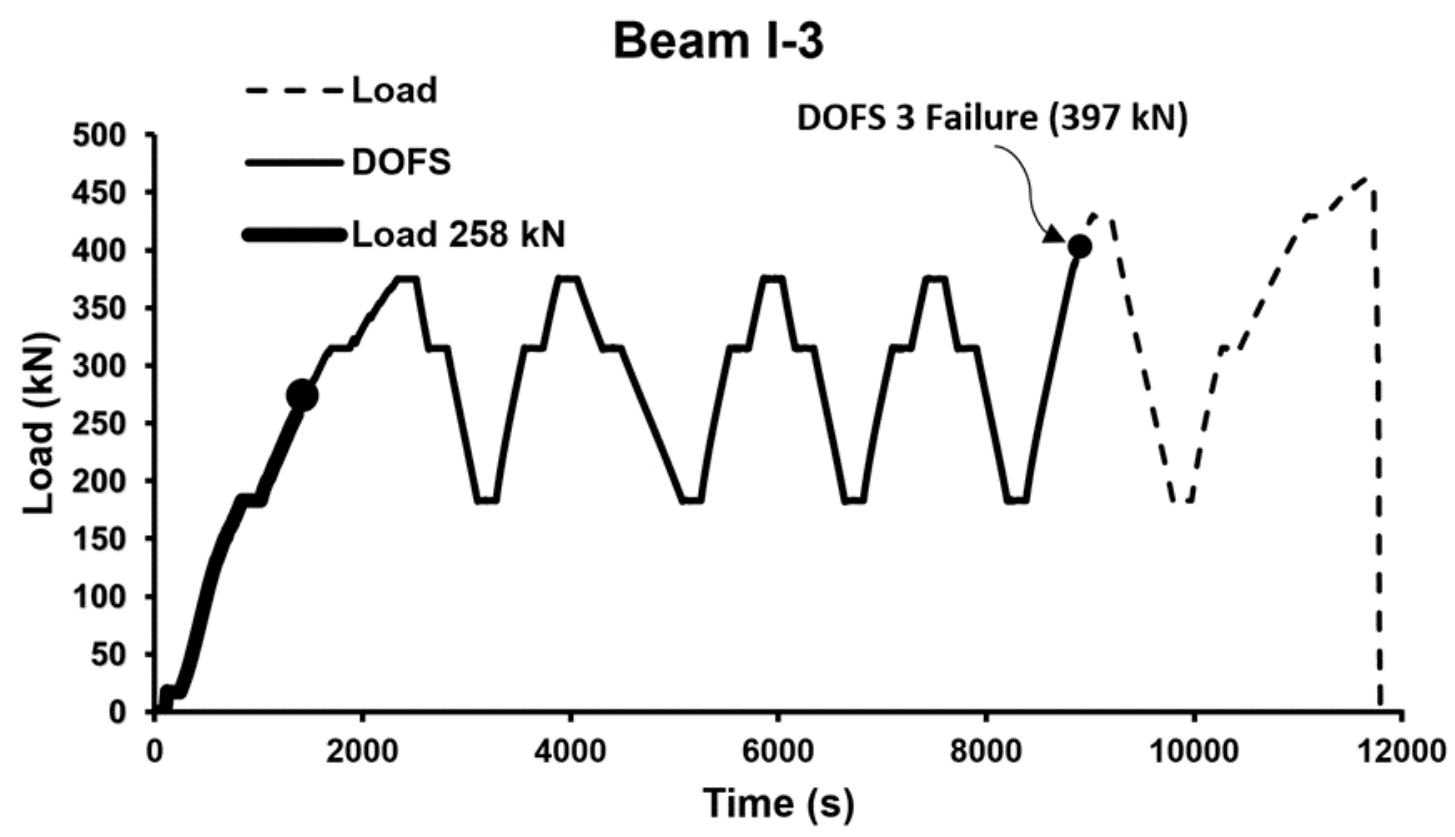

Fig. 19. Load history of beam I-3, part of the test record with DOFS and fiber break

point

In the first test, the 2D grid was made up of two distributed sensors DOFS1 (horizontal) and DOFS2 (vertical). In this case, it was not possible to obtain simultaneously the horizontal and vertical strains, as shown with black and red continuous lines in Fig 17. In the other two tests, the use of a single DOFS for monitoring both horizontal and vertical strains made possible the simultaneous measurement.

The strain records were captured every 5 seconds, and the spatial resolution was $1 \mathrm{~cm}$. In Fig. 20 is shown the strain distribution registered with the OBR system for the horizontal fiber in beam I-1 for a load level of $46.5 \mathrm{kN}$. Due to the low level of load applied, the strain at all points is lower than the cracking and therefore no cracking is still visible. 
Beam I-1

Load $=46.5 \mathrm{kN}$

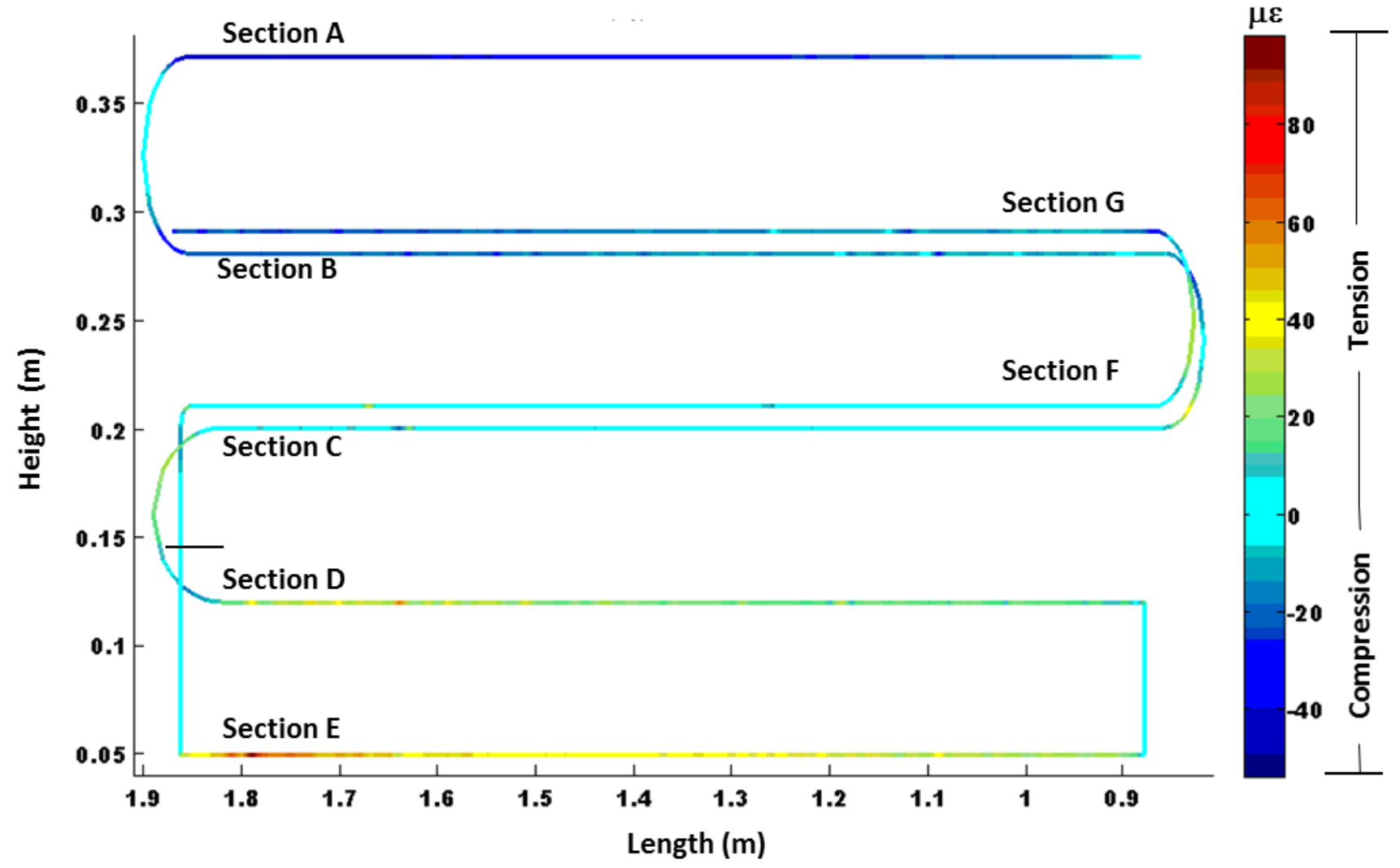

Fig. 20. Strain distribution in DOFS of beam I-1 with $Q=46.5 \mathrm{kN}$.

In Fig. 20 it can be seen how in Sections A, B and G of DOFS1 of beam I-1, mean compressive strains are slightly higher than $-40 \mu \varepsilon$. In sections $C$ and $F$, the strains are close to $0 \mu \varepsilon$, which indicates the proximity of these sections to the neutral axis. . This coincides practically with the center of gravity of the section, since the behavior of the section still remains in the elastic range.

With respect to section D (Fig. 20), which is located in the lower part of the web, tensile values slightly lower than $40 \mu \varepsilon$ are observed practically over the entire length of the DOFS1. However, in the area of section E, between 1.7 and $1.8 \mathrm{~m}$ with respect to the 
reference system tensile strains appear close to $80 \mu \varepsilon$, which indicates the feasible appearance of a crack in this area when the beam will be subject to a higher load level. In Fig. 21, the strain distribution in beam I-2 is shown for a load level of $47 \mathrm{kN}$, almost equal to that of beam I-1. It can be seen that, very similar to the case of beam I-1, section A and B present compressive stresses between -40 and $-80 \mu \varepsilon$. It can also be seen that sections $\mathrm{C}$ and $\mathrm{D}$ are found basically subject to tensile strains. In section $\mathrm{C}$, the strains are very close to $0 \mu \varepsilon$, due to their proximity to the neutral axis of the section. However, in section D the strains present values that range between 40 and $60 \mu \varepsilon$, lower still to the maximum tensile strain of the concrete. Again, no cracking was visible in the beam for this level of load.

\section{Beam I-2}

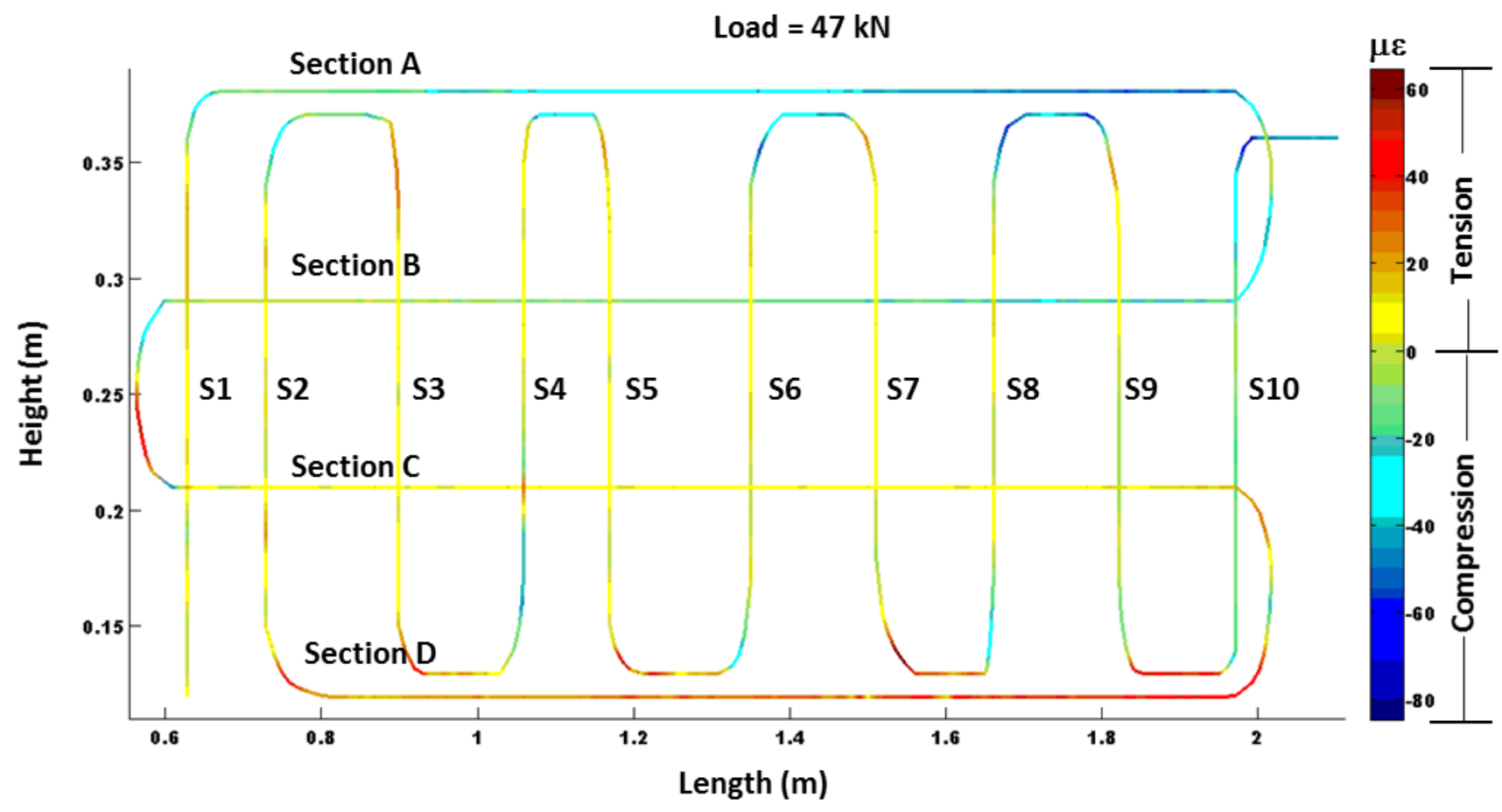

Fig. 21. Strain distribution in the DOFS of beam I-2 with $Q=47 \mathrm{kN}$. 
A similar behaviour for a load level of $47 \mathrm{kN}$ is also observed in the beam I-3 (Fig. 22)

Beam I-3

Load $=47 \mathrm{kN}$

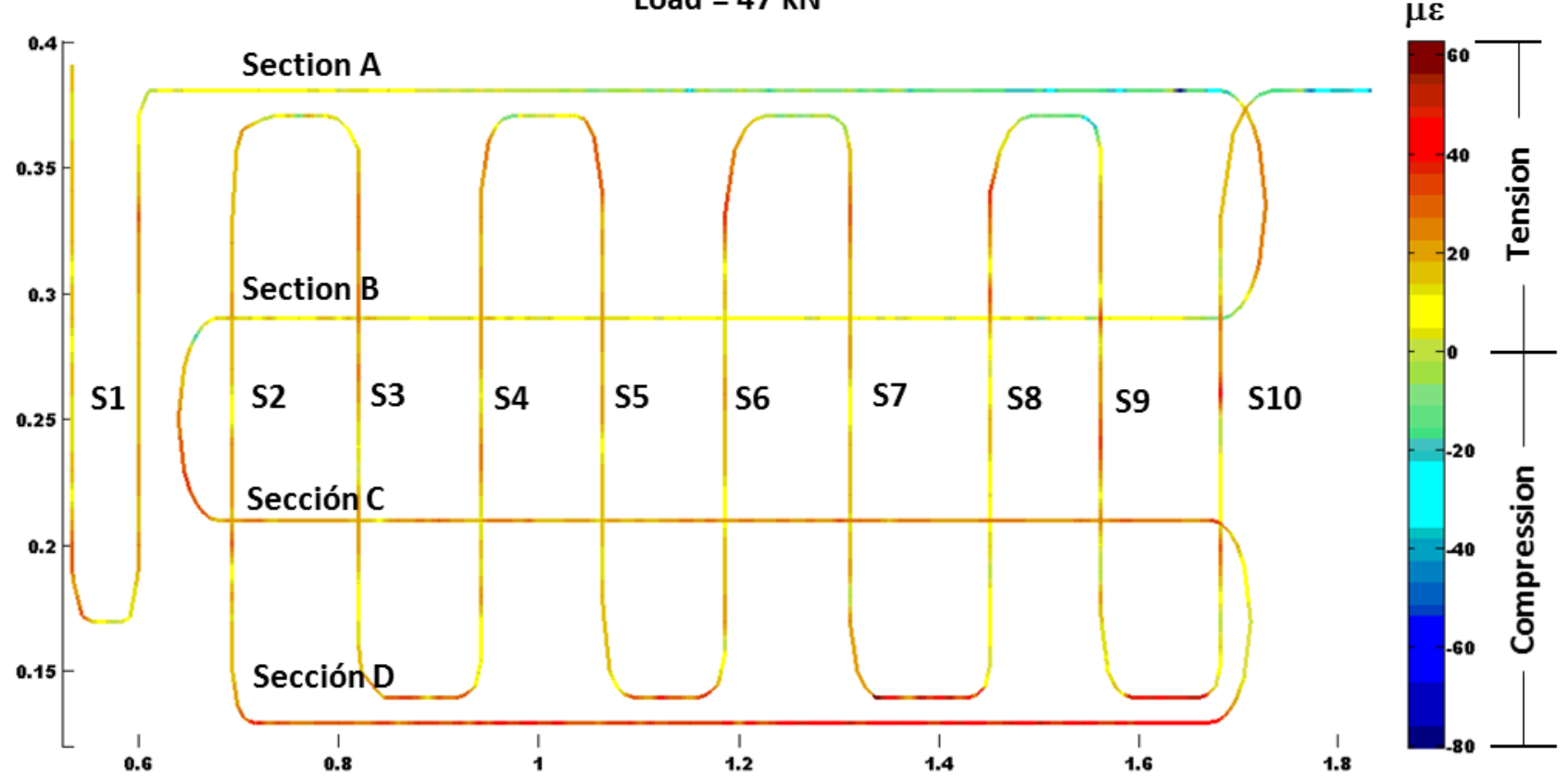

Fig. 22. Strain distribution in the DOFS of beam I-3 with $Q=47 \mathrm{kN}$.

To validate DOFS strain data obtained during the tests, the mean strains recorded between 2D grid vertical sections and instrumented stirrups near to these sections were compared (Figs. 6 to 8). Tables 4 to 6 show some strain data at different load levels obtained in stirrups S1, S3 and S5 compared to DOFS vertical sections 2, 4 and 6 in the beam I-2, which is the one that presents best correspondence between location of strain gauges and DFOS (see Figure 7 for location of stirrups S1, S3 and S5 and vertical sections 2, 4 and 6 in beam I-2). 
In the last two columns of these tables, the average strain data of the strain gauge and vertical section of the SFOD close to an instrumented stirrup are compared. The correlation is acceptable, especially between 67 and $142 \mathrm{kN}$, where the presence of shear cracks is still not important. Concerning the comparison of the values, it should be noted that strain gauges are attached to the stirrups and embedded into the concrete, whereas DOFS is bonded in the external surface and to a heterogeneous surface such as concrete. A complete description of these results is available in Rodriguez, 2017.

Table 4. Beam I-2. Stirrup S1. Strains at different heights, mean value and comparison with mean strain of DOFS in vertical section 2.

\begin{tabular}{|c|c|c|c|c|c|}
\hline $\begin{array}{c}\text { Load } \\
(\mathrm{kN})\end{array}$ & $\begin{array}{c}\text { S1Gh1 } \\
\mu \mathrm{m} / \mathrm{m}\end{array}$ & $\begin{array}{c}\text { S1Gh2 } \\
\mu \mathrm{m} / \mathrm{m}\end{array}$ & $\begin{array}{c}\text { S1Gh3 } \\
\mu \mathrm{m} / \mathrm{m}\end{array}$ & $\begin{array}{c}\text { S1 mean } \\
\mu \mathrm{m} / \mathrm{m}\end{array}$ & $\begin{array}{c}\text { DOFSsecc2 } \\
\mu \mathrm{m} / \mathrm{m}\end{array}$ \\
\hline 67 & 4.0 & 4.9 & 9.9 & 6.3 & 14.1 \\
77 & 4.1 & 5.2 & 11.5 & 6.9 & 15.6 \\
88 & 4.6 & 5.7 & 13.2 & 7.8 & 17.5 \\
95 & 6.5 & 7.4 & 14.5 & 9.5 & 18.6 \\
100 & 6.2 & 7.6 & 15.7 & 9.8 & 19.0 \\
115 & 17.4 & 12.9 & 18.1 & 16.1 & 22.6 \\
124 & 29.8 & 17.4 & 19.8 & 22.3 & 24.6 \\
142 & 43.2 & 27.7 & 26.2 & 32.4 & 30.4 \\
203 & 537.2 & 1398.7 & 1109.1 & 1015.0 & 944.5 \\
213 & 705.4 & 1559.9 & 1276.2 & 1180.5 & 219.7 \\
224 & 811.3 & 1658.6 & 1384.9 & 1284.9 & 1267.8 \\
290 & 2243.4 & 3170.5 & 2140.3 & 2518.1 & 3078.3 \\
\hline
\end{tabular}


Table 5. Beam I-2. Stirrup S3. Strains at different heights, mean value and comparison with mean strain of DOFS in vertical section 4.

\begin{tabular}{|c|c|c|c|c|c|}
\hline $\begin{array}{c}\text { Load } \\
(\mathrm{kN})\end{array}$ & $\begin{array}{l}\text { S3Gh1 } \\
\mu \mathrm{m} / \mathrm{m}\end{array}$ & $\begin{array}{l}\text { S3Gh2 } \\
\mu \mathrm{m} / \mathrm{m}\end{array}$ & $\begin{array}{l}\text { S3Gh3 } \\
\mu \mathrm{m} / \mathrm{m}\end{array}$ & $\begin{array}{c}\text { S3 mean } \\
\mu \mathrm{m} / \mathrm{m}\end{array}$ & $\begin{array}{l}\text { DOFSsecc4 } \\
\mu \mathrm{m} / \mathrm{m}\end{array}$ \\
\hline 67 & -2.7 & 5.6 & 18.8 & 7.2 & -1.6 \\
77 & -6.0 & 4.4 & 21.0 & 6.4 & -2.6 \\
88 & -3.5 & 6.4 & 24.7 & 9.2 & -4.1 \\
95 & 2.9 & -0.7 & 21.6 & 8.0 & -3.8 \\
100 & 15.9 & 7.5 & 24.6 & 16.0 & -3.9 \\
115 & 13.8 & 2.3 & 26.2 & 14.1 & 0.7 \\
124 & 111.4 & 108.2 & 31.0 & 83.5 & 4.2 \\
142 & 242.0 & 424.4 & 37.9 & 234.8 & 13.8 \\
203 & 1292.7 & 1951.0 & 1410.8 & 1551.5 & 1910.3 \\
213 & 1438.5 & 2059.1 & 1615.1 & 1704.3 & 2236.2 \\
224 & 1609.0 & 2162.7 & 1794.7 & 1855.5 & 1400.7 \\
290 & 3072.0 & 3329.9 & 3056.5 & 3152.8 & 3891.3 \\
\hline
\end{tabular}

Table 6. Beam I-2. Stirrup S5. Strains at different heights, mean value and comparison with mean strain of DOFS in vertical section 6.

\begin{tabular}{|c|c|c|c|c|c|}
\hline $\begin{array}{c}\text { Load } \\
(\mathrm{kN})\end{array}$ & $\begin{array}{l}\text { S5Gh1 } \\
\mu \mathrm{m} / \mathrm{m}\end{array}$ & $\begin{array}{l}\text { S5Gh2 } \\
\mu \mathrm{m} / \mathrm{m}\end{array}$ & $\begin{array}{l}\text { S5Gh3 } \\
\mu \mathrm{m} / \mathrm{m}\end{array}$ & $\begin{array}{c}\text { S5 mean } \\
\mu \mathrm{m} / \mathrm{m}\end{array}$ & $\begin{array}{l}\text { DOFSsecc6 } \\
\mu \mathrm{m} / \mathrm{m}\end{array}$ \\
\hline 67 & -12.1 & -5.5 & 15.0 & -0.9 & 4.0 \\
77 & 16.9 & 3.4 & 18.9 & 13.1 & 2.0 \\
88 & -59.6 & -13.9 & 23.1 & -16.8 & 2.3 \\
95 & 46.5 & -35.8 & 13.6 & 8.1 & 2.5 \\
100 & 142.2 & -15.9 & 4.9 & 43.8 & 16.4 \\
115 & 199.6 & 304.7 & 14.5 & 172.9 & -4.3 \\
124 & 237.7 & 676.0 & -0.8 & 304.3 & 55.6 \\
142 & 266.9 & 961.1 & 256.8 & 495.0 & 95.1 \\
203 & 922.3 & 1680.7 & 1693.5 & 1432.2 & 2147.5 \\
213 & 1083.3 & 1804.5 & 1785.8 & 1557.9 & 1355.0 \\
224 & 1284.5 & 1914.9 & 1881.2 & 1693.5 & 1917.3 \\
290 & 2389.3 & 2898.5 & 2943.5 & 2743.8 & 3355.5 \\
\hline
\end{tabular}




\section{Crack detection}

During the tests and to establish the order of appearance of the craks, the OBR system was programmed to record strain data every $5 \mathrm{~s}$ along the SFOD length. Also and thanks to $1 \mathrm{~cm}$ OBR spatial resolution, the strain variation in the web could be obtained. In this way, both strain profiles in horizontal and vertical direction were obtained simultaneously. The strain evolution versus load level from 47 to $171 \mathrm{kN}$ in the three tested beams are shown from Figs. 23 to 28. In these figures the horizontal and vertical stitch line indicates the concrete maximum tensile strain. A value over this threshold indicates that cracking starts. With a previous established coordinate system, the locations of the cracks were obtained. .

The strain evolution before cracking and the crack appearance can be detected, localized and quantified in terms of micro strains. The detection, localization and progression of one or more cracks as load is increased is represented using bold points. Once the shear crack points have been located, it is also possible to obtain the cracking patterns in the web for increasing load levels as presented in figure 29 for loads of 106, 115 and $171 \mathrm{kN}$ respectively. A complete description of this shear crack patterns is available in Rodriguez, 2017. 


\section{Beam I-1}
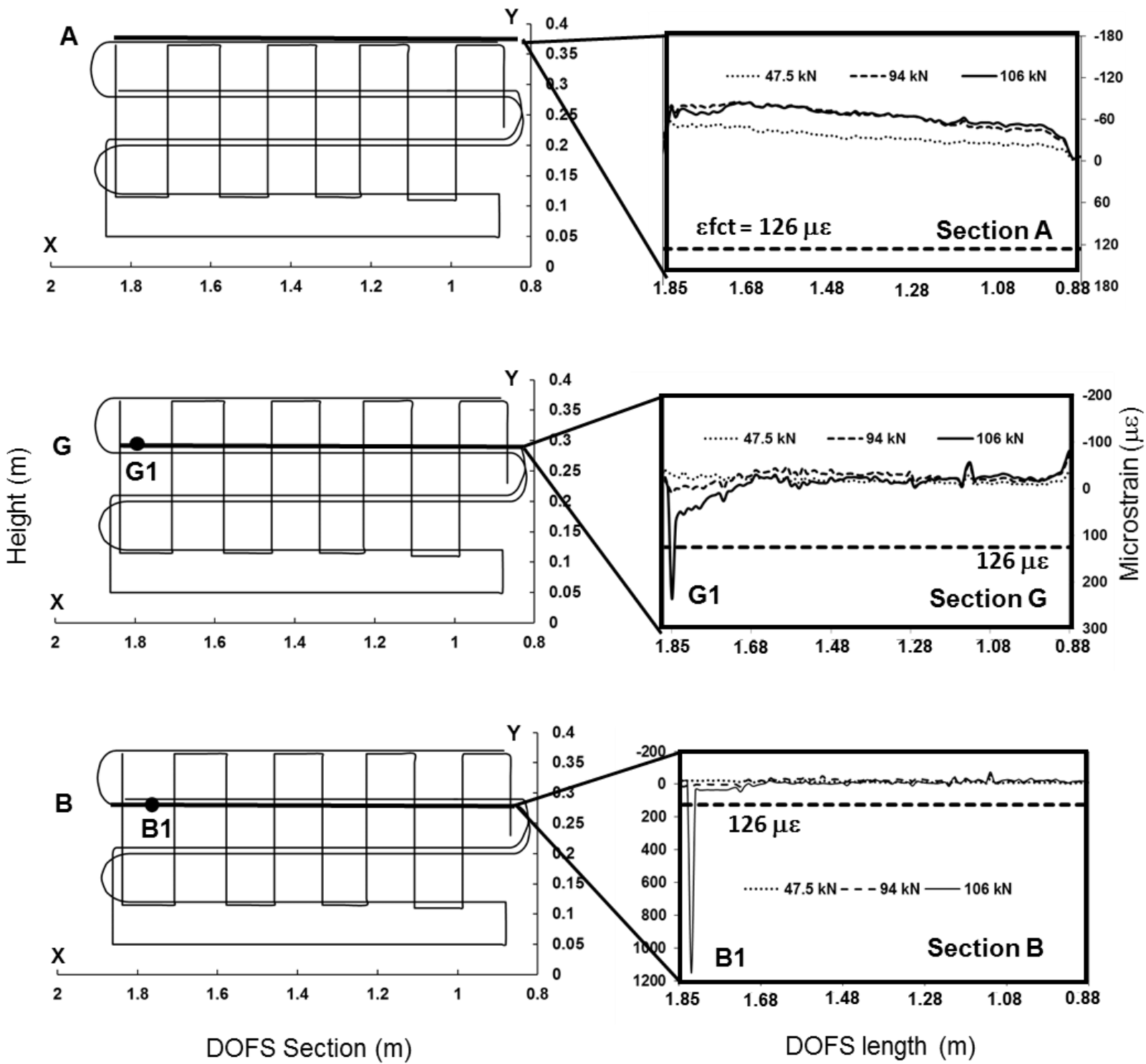

Fig. 23. Strain distribution in horizontal sections A, G and B of beam I-1 at different load levels. 


\section{Beam I-1}
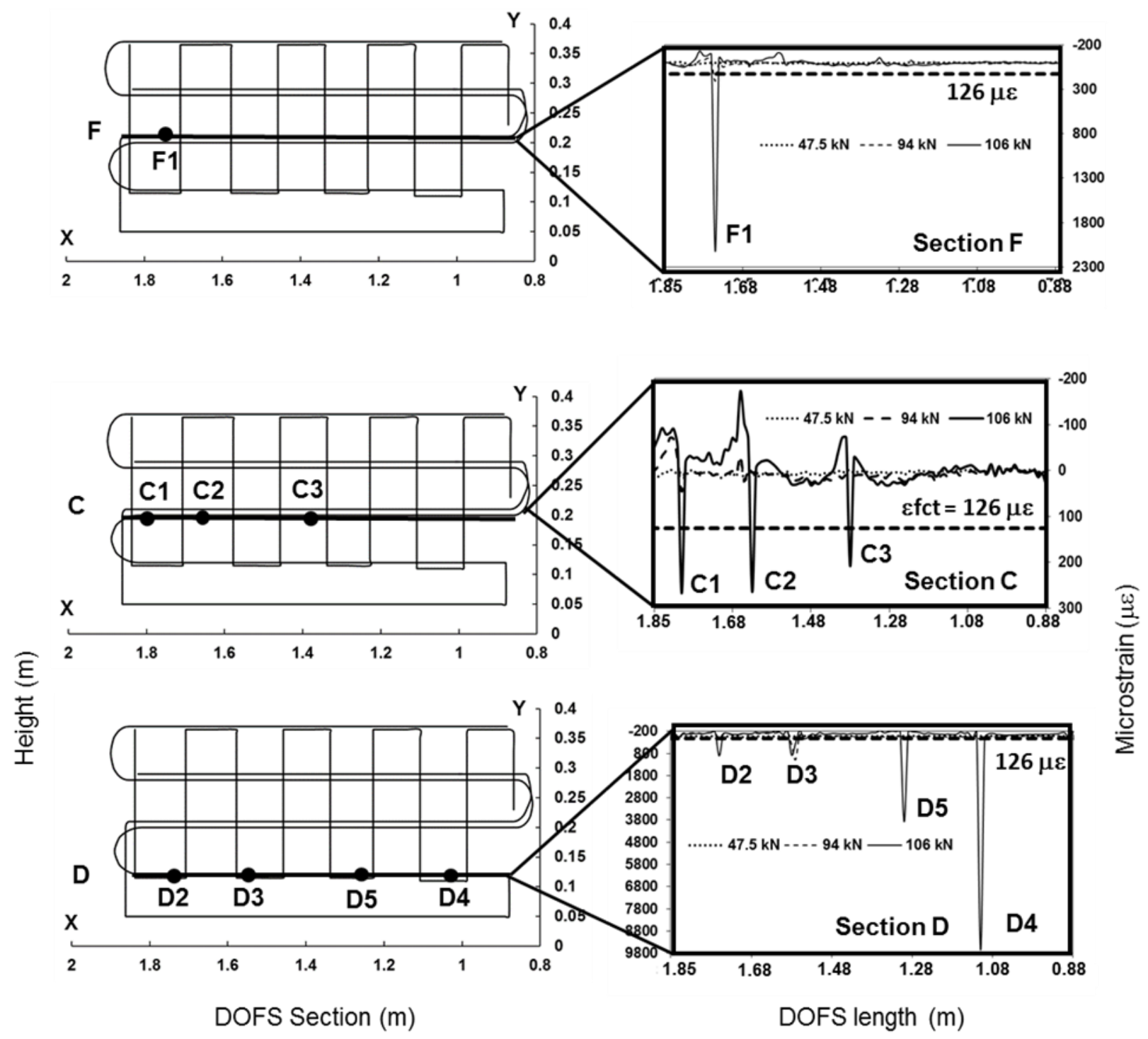

Fig. 24. Strain distribution in horizontal sections $F, C$ and $D$ of beam I-1 at different load levels. 


\section{Beam I-2}
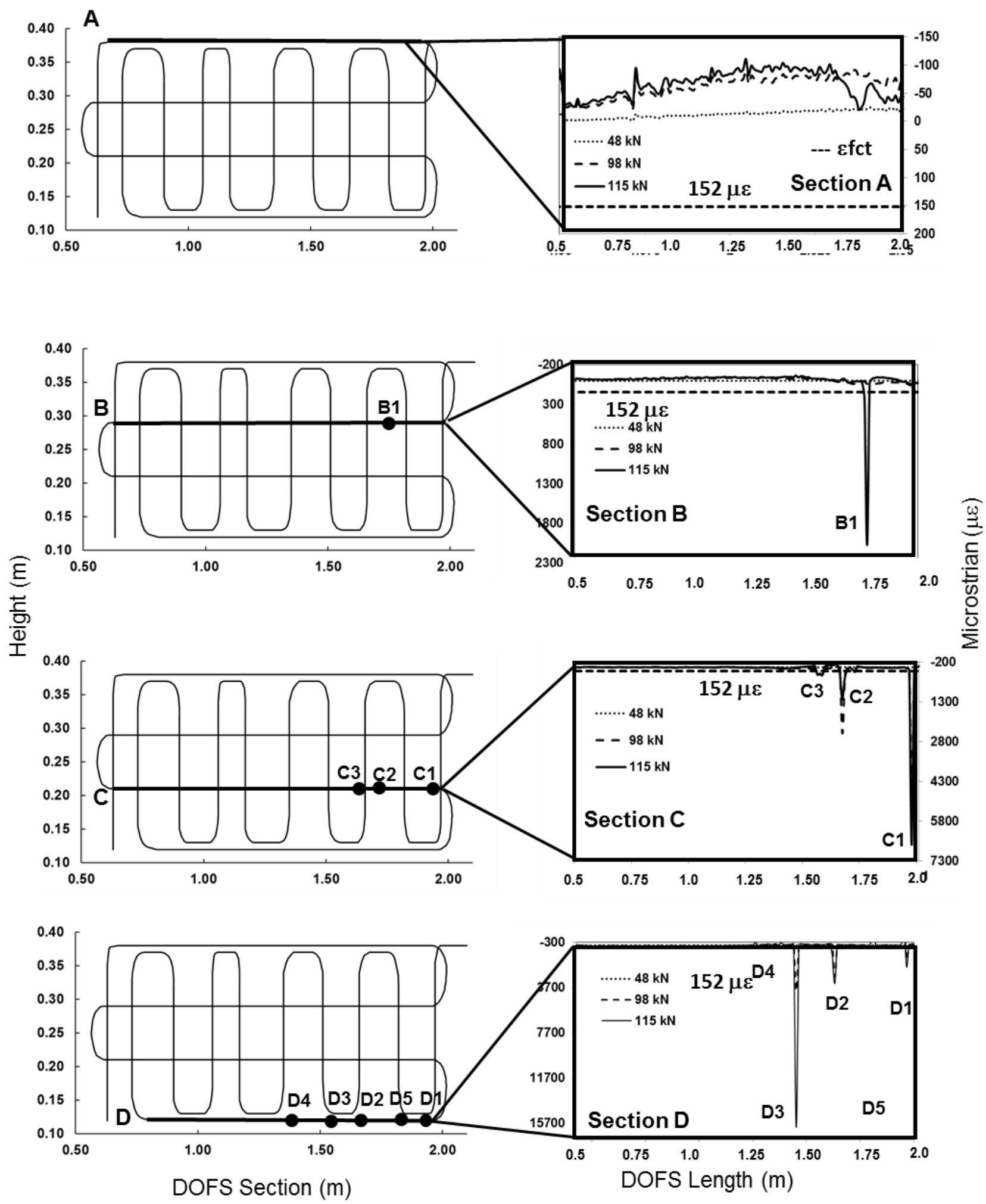

Fig. 25. Strain distribution in horizontal sections of beam I-2 at different load levels. 
Beam I-2
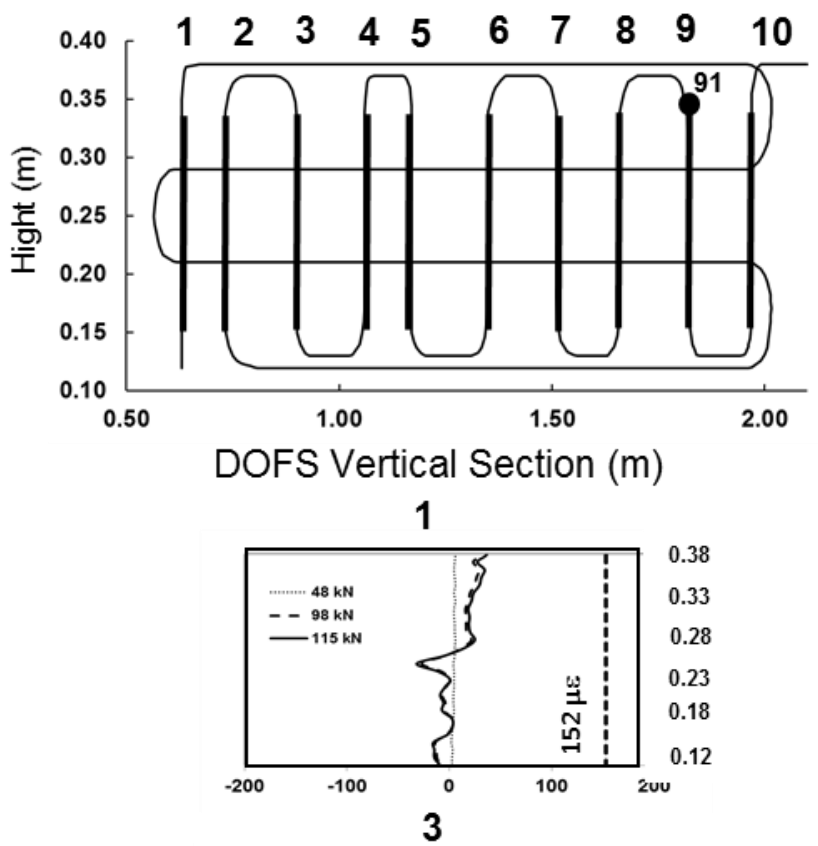

2

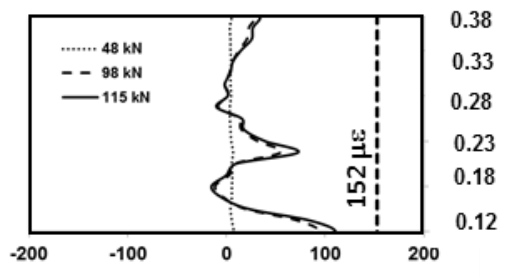

5

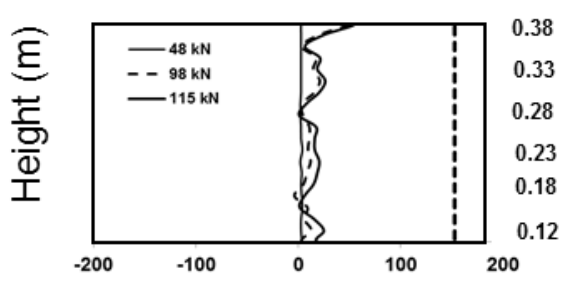

8

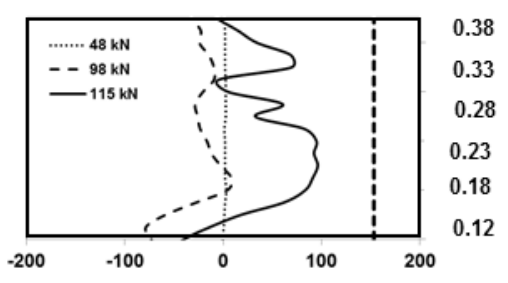

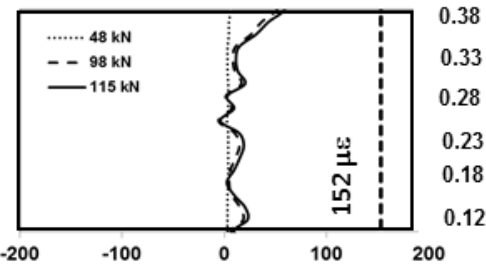

6

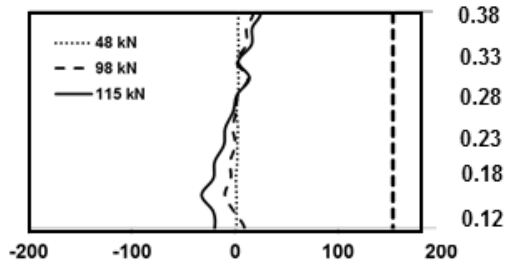

9

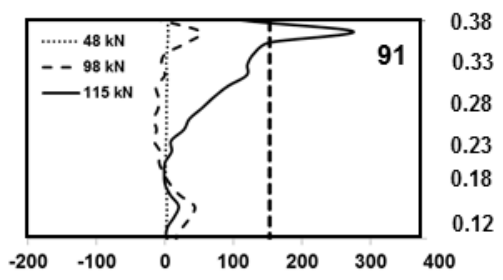

10

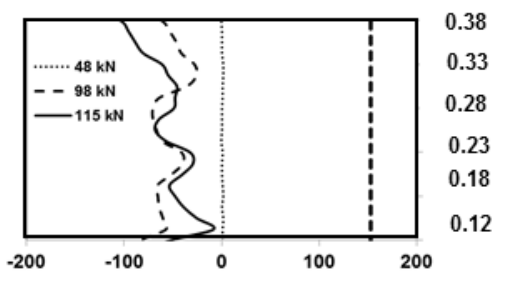

28

0.23

0.18

Microstrain $(\mu \varepsilon)$

Fig. 26. Strain distribution in vertical sections of beam I-2 at different load levels. 


\section{Beam I-3}
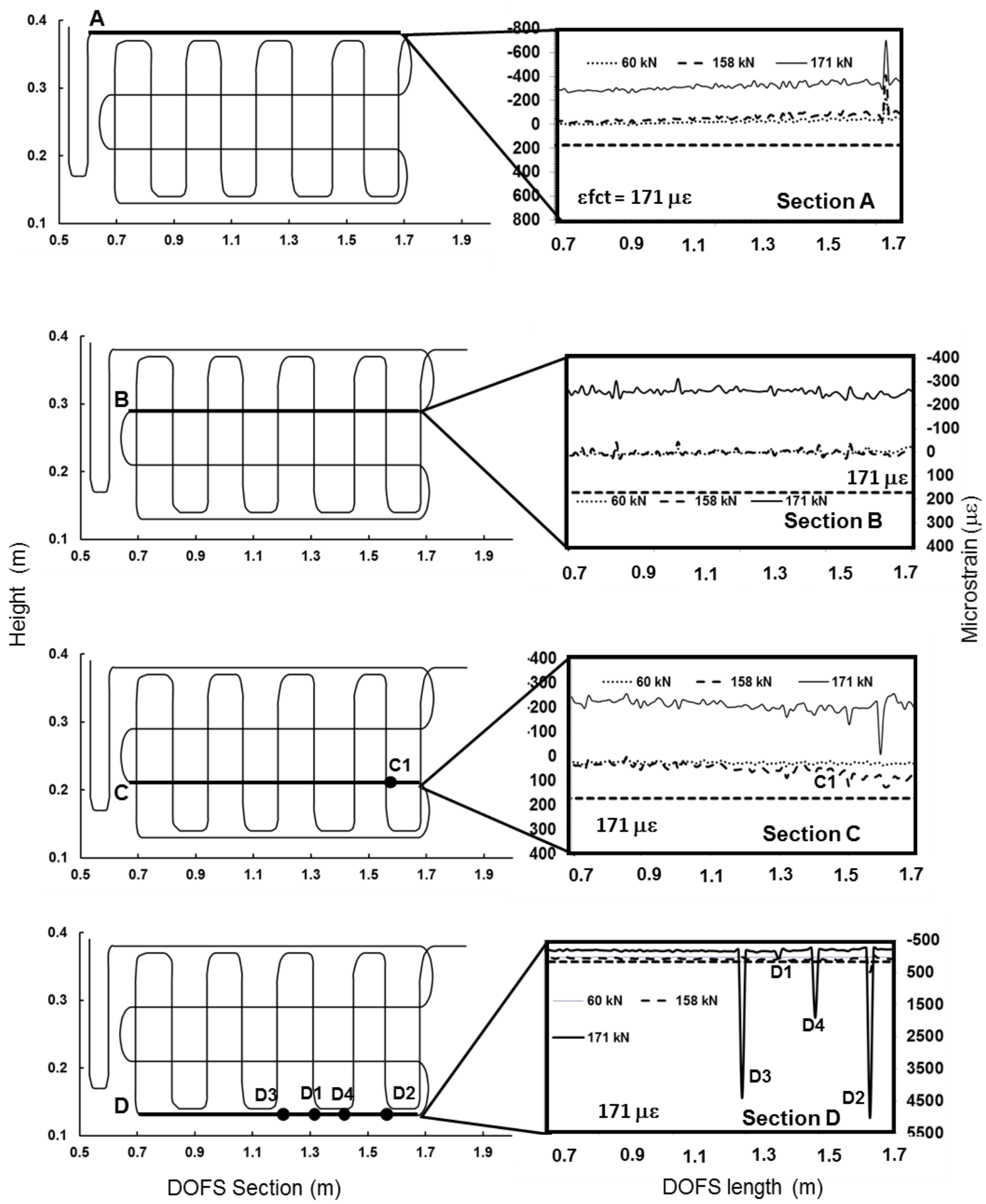

Fig. 27. Strain distribution in horizontal sections of beam I-3 at different load levels. 
Beam I-3

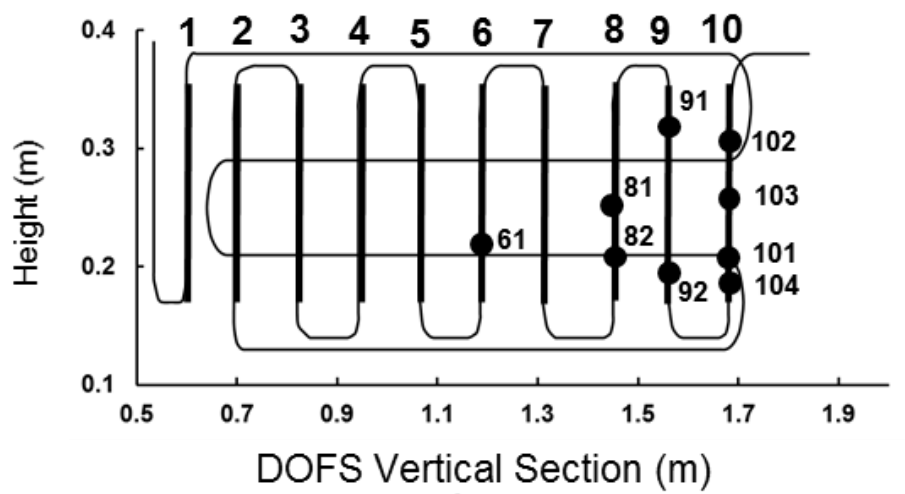

2

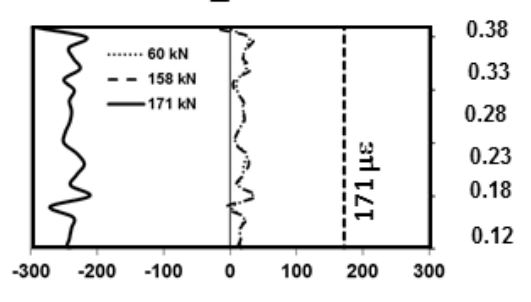

5

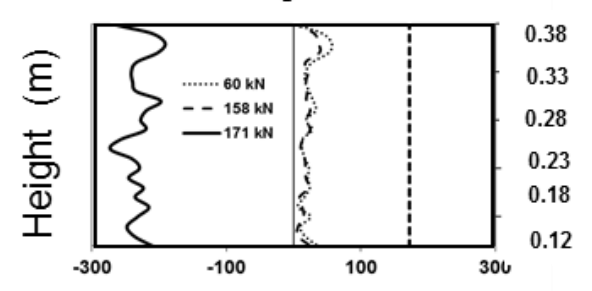

8

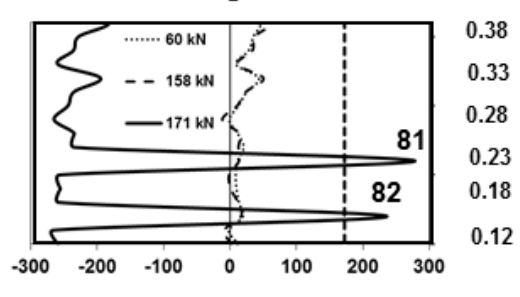

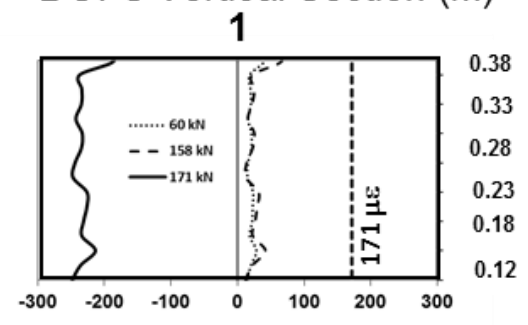
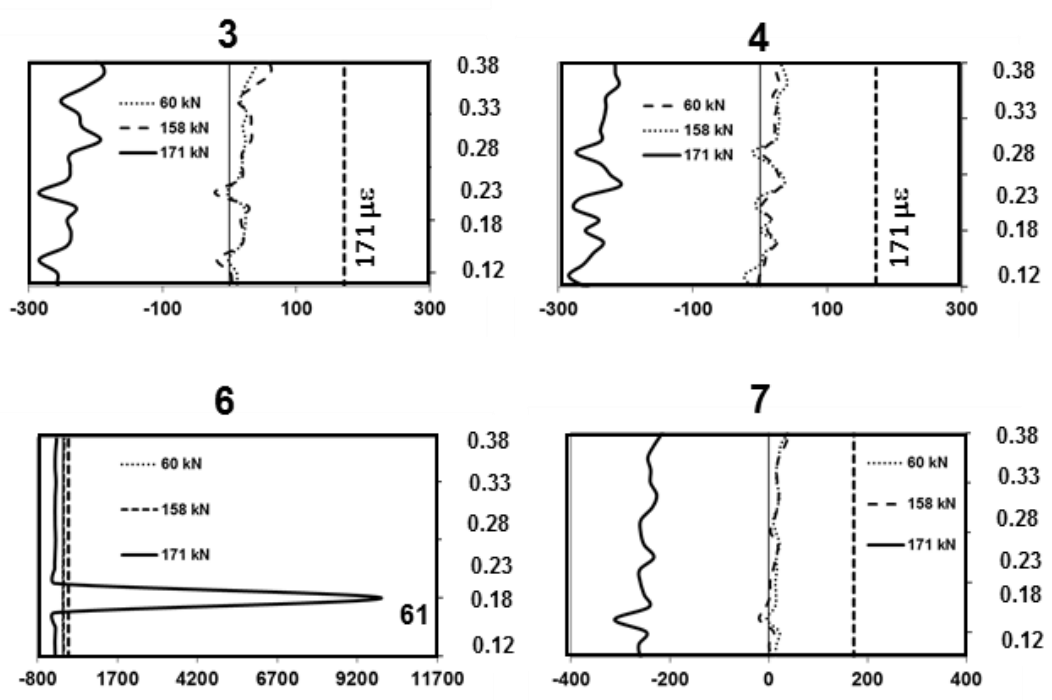

9
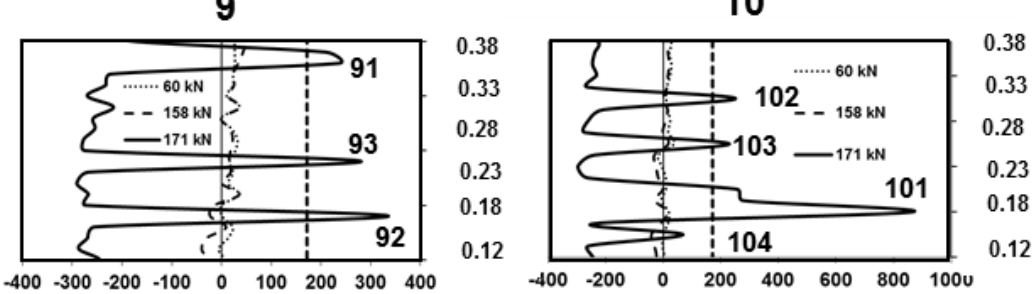

Microstrain $(\mu \varepsilon)$

Fig. 28. Strain distribution in vertical sections of beam I-3 at different load levels. 


\section{Beam I-1}
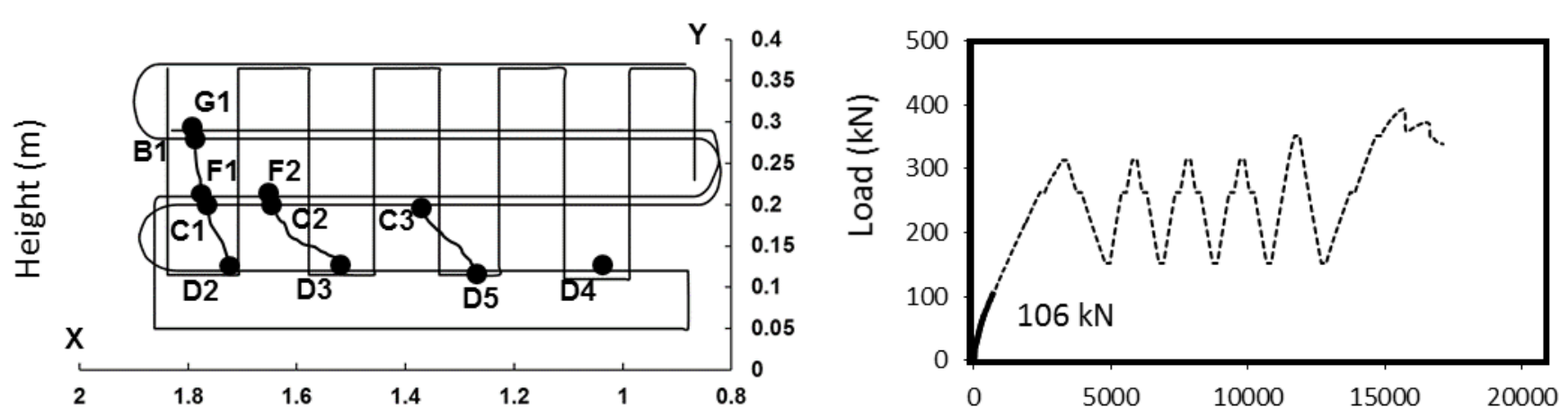

Beam I-2
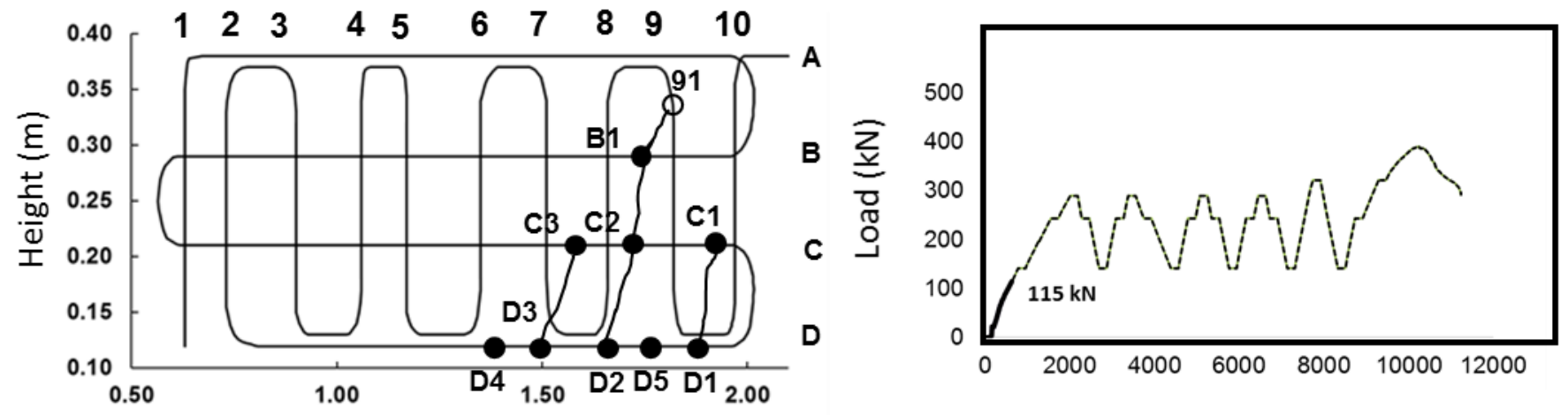

Beam I-3

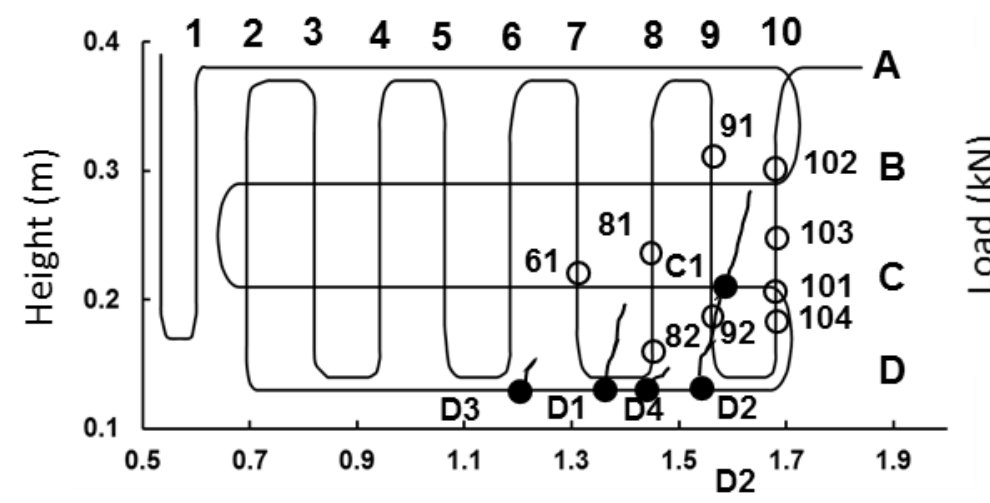

DOFS length $(\mathrm{m})$

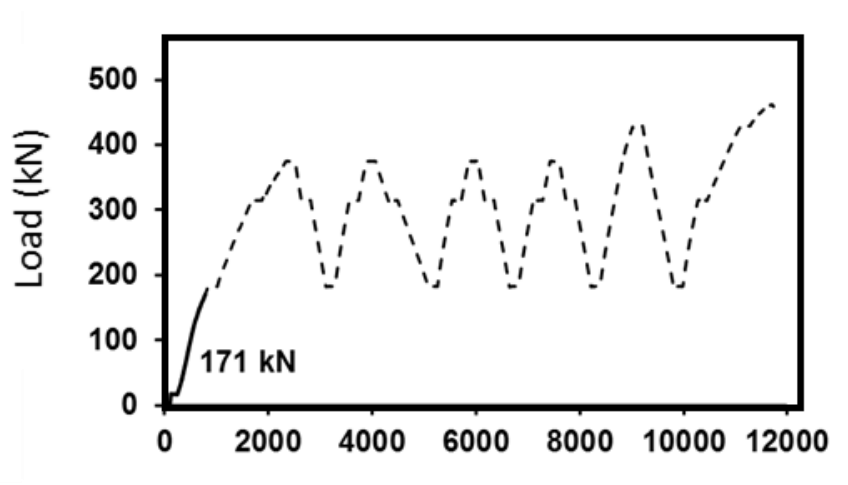

Time (s)

Fig. 29. Shear crack patterns of beams I-1, I-2 and I-3 at different load levels obtained with the DFOS data. 
The shear crack patterns in the beams obtained with the DOFS strain data were validated thanks to the visual inspection carried out and photos taken during the test execution.

As an example, in Fig. 30 are compared the crack patterns obtained with the DOFS and by visual inspection for a load level of $187 \mathrm{kN}$ in the beam I-1. As can be seen, the agreement is excellent.
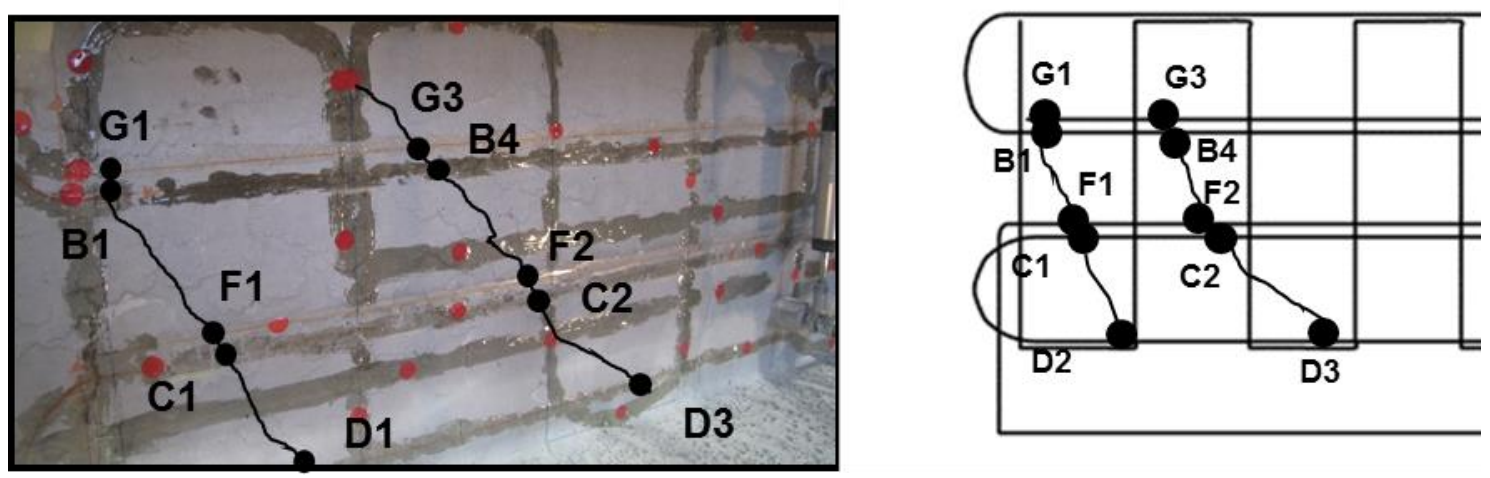

Fig. 30. Comparison of the real cracking pattern and obtained with DFOS in beam I-I at a load of $187 \mathrm{kN}$

In Fig. 31, the results in the beam I-2 are compared. The load at this point was $203 \mathrm{kN}$.
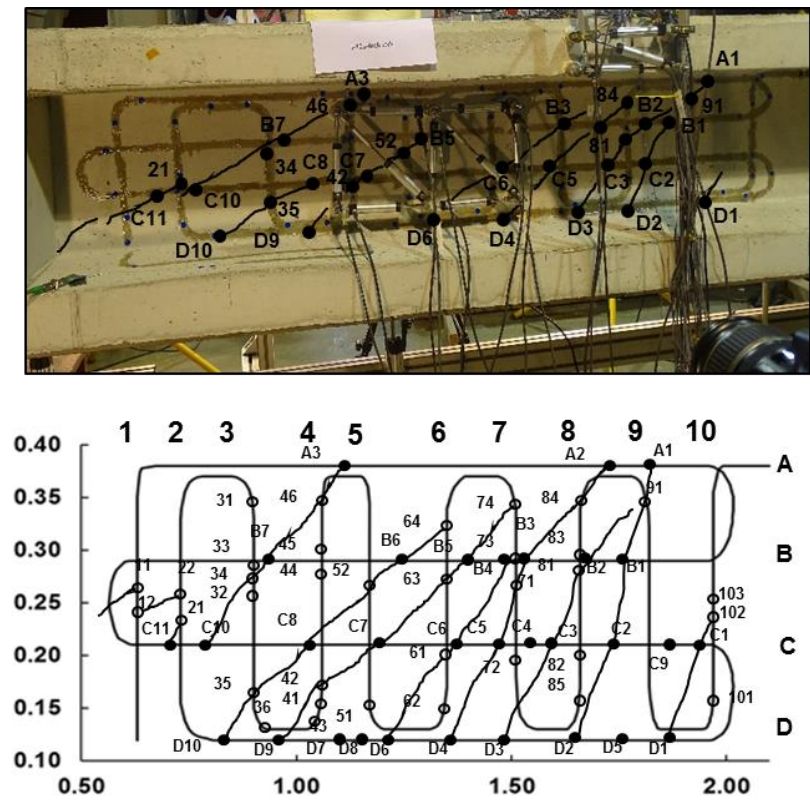

Fig. 31. Comparison of the real cracking pattern and obtained with DFOS in beam I-2 at a load of $203 \mathrm{kN}$ 
From the results analyzed, it should be pointed out that there are some cracking points that do not coincide with the trace of the shear crack pattern obtained from the visual inspection. These differences can be due to points that at higher load levels will be part of the formation of other cracks, damage in the bonding of the fiber, presence of small cavities in the concrete surface, and effects caused by the high strain level in the optical fiber. The points that do not coincide with the shear crack pattern are shown in Fig31 using a circle point.

A comparison between the real cracking pattern in the beam I-3 at load level of $325 \mathrm{kN}$ and the calculated cracking pattern for a load level of $258 \mathrm{kN}$ is shown in Fig. 32. In this case, the results from the visual inspection for the corresponding load level are not available.
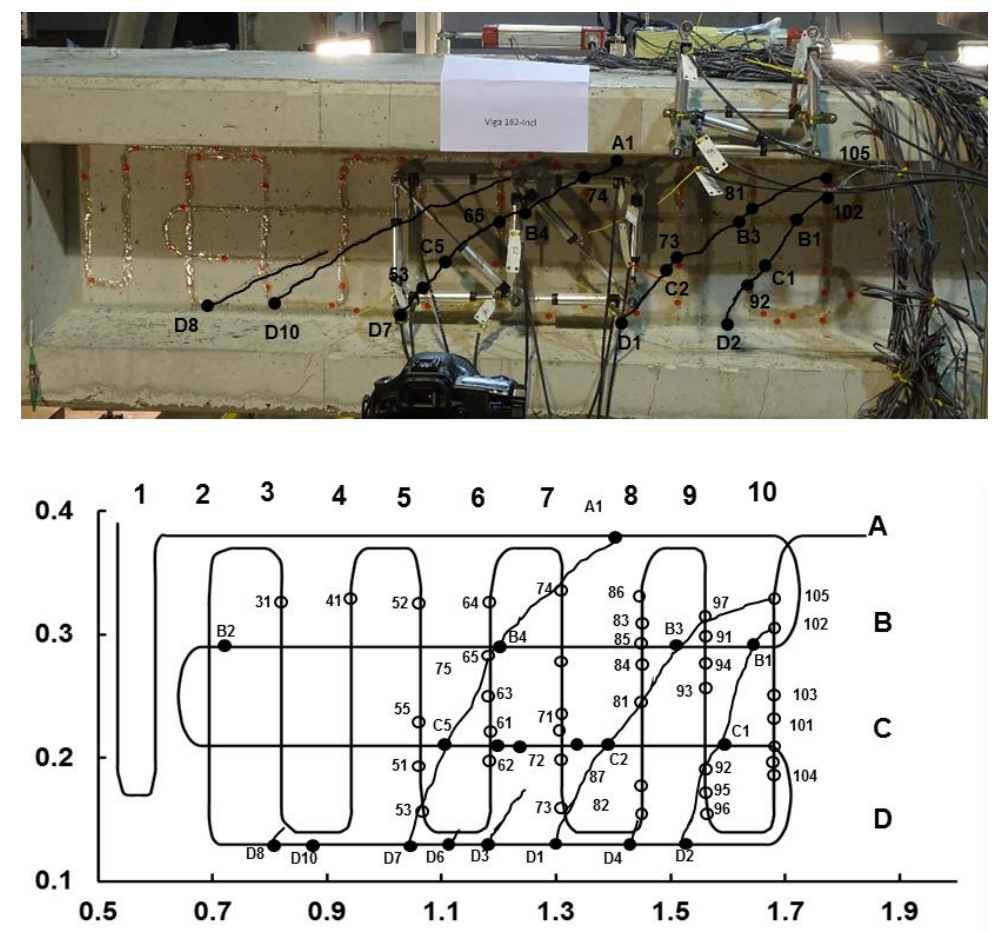

Fig. 32. Comparison between the actual shear pattern of beam I-3 at $325 \mathrm{kN}$ (up) and the calculated cracking pattern at $258 \mathrm{kN}$ (down). 
It is important to notice that from a certain level of load (and consequently of cracking and strain in the fiber optic), the results of the DFOS cannot be considered reliable. For instance, this is the case of beam I-1 beyond the load of $260 \mathrm{kN}$. In Fig. 33 are shown the results in stretch B for this beam.

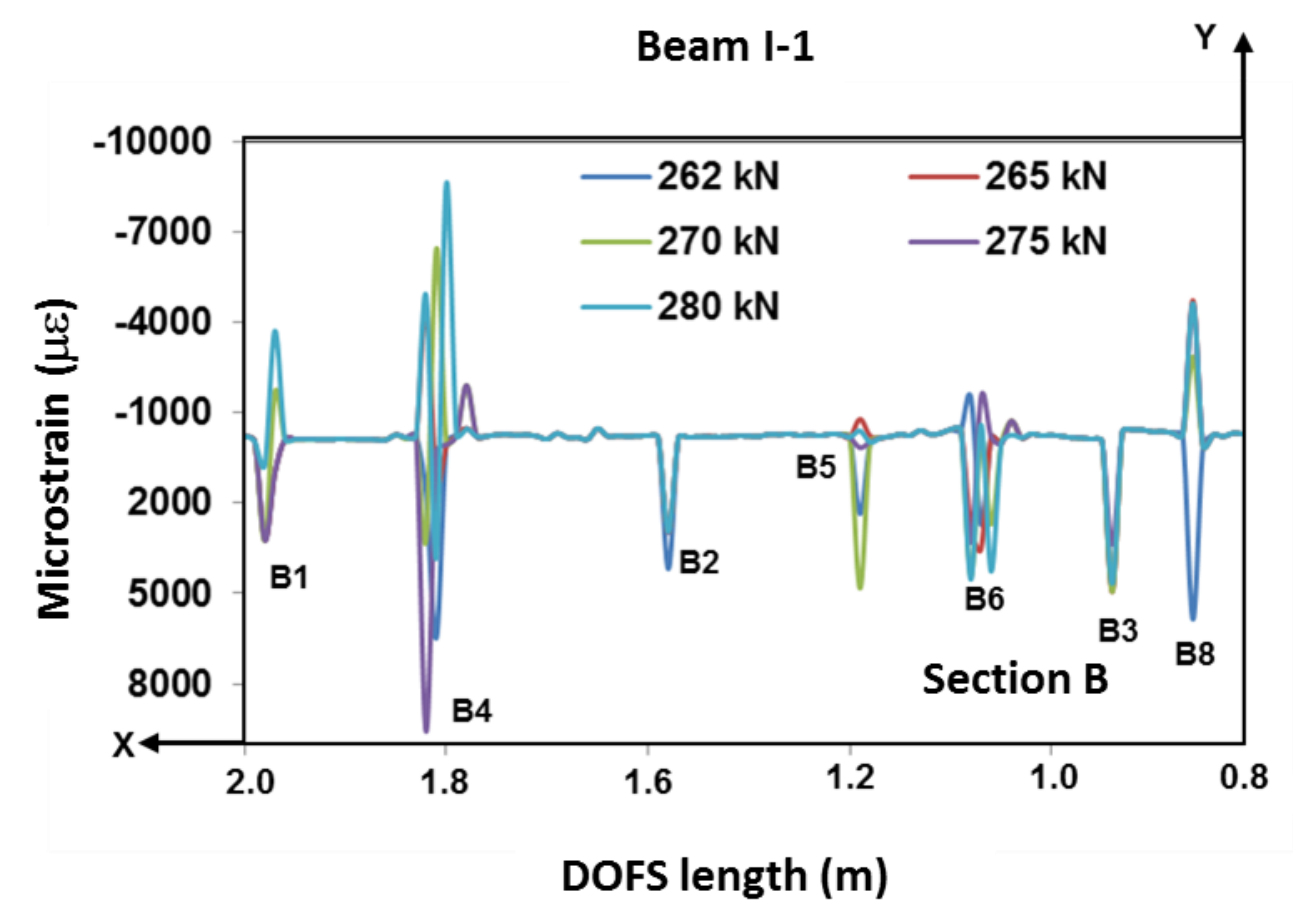

Fig. 33. Strains in section B of DOFS1 of beam I-1 at load levels above $262 \mathrm{kN}$.

Eight peaks associated with cracking points were identified in stretch B at $262 \mathrm{kN}$. After this point, maximum strains close to $10,000 \mu \varepsilon$ were recorded, which are not feasible values. Also, alternative strain changes from tension to compression are observed, showing an incorrect performance of the sensor. This behavior is associated to SSQ (Spectral Shifht Quality) values lower than 0.15, where, according to the manufacturer of the OBR system, the recorded values cannot be considered as accurate.

Therefore, detection and location of shear cracks is limited to strain levels around $250 \mathrm{kN}$ for this particular beam, which correspond to maximum strains in the fiber around 3000 $\mu \varepsilon$. Similar results were found in the other beams, where for a load levels higher than 265 
$\mathrm{kN}$ the lectures were not reliable. Also in these cases, the maximum load levels with correct performance of the DOFS correspond to strain levels around $3000 \mu \varepsilon$. In any case, these load levels produce high cracking and large deflections and therefore are far beyond the normal service load levels expected in real structures. Therefore, SHM in shear for concrete structures in service is completely feasible using this technique according to the strain values expected and the results obtained in the tests.

The results presented here open the way to several possibilities obtain information that is useful for an adequate diagnosis of a structural system, such as the strain profile analysis, the trace of the cracking patterns and the calculation of the crack width. This offers an interesting application in the field of SHM of concrete structures. These possibilities have been already shown in the case of concrete elements (beam and slab) in bending (Villalba and Casas 2013, Rodriguez et al 2015 a). The extension to shear has been shown here.

\section{Conclusions}

The potential application of DOFS in the SHM of shear cracking in concrete structures was the main purpose of the tests described. The results obtained have shown the feasibility to do that by deploying the DOFS forming a 2D mesh in the area of interest of the concrete element.

A methodology is presented, not only to detect cracking, but also to locate the cracks and thus, allowing to conform the corresponding cracking patterns in the element due to the shear effect. It is also possible to monitor the evolution of the cracking pattern for different levels of load. The method has been checked in a series of laboratory tests carried out in partially pre-stressed concrete beams. 
In the first instance, the peaks that appear in the strain profiles can be associated with the presence of cracks, which, thanks to the high resolution and sensitivity of the DOFS monitoring system, can be detected even before they were seen during a visual inspection. The grid formed by the DOFS deployed in horizontal and vertical directions allowed to define the crack pattern as load was increasing, despite the different inclination of the cracks along the web height. This was possible up to a maximum load level that in the present tests was in the range of $250-265 \mathrm{kN}$ depending on the beam. The associated maximum strain level measured with the DOFS is around $3000 \mu \varepsilon$. After this maximum level, the sensors are recording not reliable data. In any case, these values produce strain values and crack widths that are much higher than those expected in normal service conditions in real concrete structures. Therefore, the proposed method can be seen as a feasible technique for the SHM of concrete elements subjected to shear actions.

\section{Acknowledgments}

The authors want to knowledge the financial support provided by the Spanish Ministry of Economy and Innovation through research projects BIA2013-47290-R, BIA201236848 and FEDER (European Regional Development Funds), and special thanks to Ulric Celada for sharing experiences during the instrumentation and execution of the laboratory tests.

\section{References}

Bazant Z.P. (1983) Crack band theory for fracture of concrete. Materials and Structures; $16 ;$ pp 155-177.

Barosnyói A. and Balázs G.L. (2005) Models for flexural cracking in concrete: the state of the art. Structural Concrete, 6, No. 2; pp 53-62.

Bairan J., Santos D., Duarte N., Marí A. and Celada U. (2014). Control de la fisuración a cortante y flexión mediante pretensado parcial (in spanish). VI Congreso de ACHE. Madrid Spain, 17-19 june. 
Barrias A., Rodríguez G., Casas J.R.. and Villalba S. (2018a), Applications of distributed optical fiber sensors for the health monitoring of two real structures in Barcelona. Structure and Infrastructure Engineering. DOI: 10.1080/15732479.2018.1438479

Barrias A., Casas J.R., and Villalba S. (2018b), Performance analysis of distributed optical fiber bonding adhesives to concrete. Proceedings of 9th International Conference on Bridge Maintenance, Safety and Management, IABMAS 2018, Melbourne, Australia

Barrias A., Casas J.R, and Villalba S. (2018c), On the bonding performance of distributed optical fiber sensors (DOFS) in structural concrete. Proceedings of The Sixth International Symposium on Life-Cycle Civil Engineering, IALCCE 2018, Ghent, Belgium.

Barrias, A., Casas, J.R., and Villalba, S. (2018d), Embedded Distributed Optical Fiber Sensors in Reinforced Concrete Structures. A case study". Sensors, 18, 980. DOI:10.3390/s18040980

Barrias A., Casas J.R., and Villalba S. (2016), A review of distributed optical fiber sensors for civil engineering applications". Sensors, 16, 748. DOI:10.3390/s16050748

Casas J.R., Villalba S. and Villalba V. (2014) "Management and safety of existing concrete structures via optical fiber distributed sensing". Chapter of the book "Maintenance and Safety of Aging Infrastructure". Dan M. Frangopol and Yiannis Tsompanakis, Editors. CRC Press. Taylor and Francis.

Celada, U. (2015), "Estudio teórico y experimental sobre el comportamiento en servicio y en rotura de elementos isostáticos de hormigón parcialmente pretensados sometidos a flexión y cortante". Ph. D Thesis in progress, Technical University of Catalonia, UPC, Barcelona (in Spanish)

Davis, M.; Hoult, N.A.; Scott, A. (2016). Distributed strain sensing to determine the impact of corrosion on bond performance in reinforced concrete. Constr. Build. Mater. $114,481-491$.

Davis, M.; Hoult, N.A.; Scott, A. (2017). Distributed strain sensing to assess corroded RC beams. Eng. Struct., 140, 473-482.

De Silva S., Mutsuyoshi H. and Witchukreangkrai E. (2008) Evaluation of shear crack width in shaped prestressed reinforced concrete beams. Journal of Advanced Concrete Technology. Vol. 6, No. \#. Japan Concrete Institute, October; pp 443-458.

Hoult N.A., Ekim O. y Regier R. (2014) "Damage/Deterioration for Steel Structures Using Distributed Fiber Optic Stress Sensors", ASCE Journal of Engineering Mechanics, October, 1-9

LUNA. (2012)b, Optical Distributed Sensor Interrogator (ODiSI- A). 
LUNA, 2017, Application Note, ODiSI Sensor installation guide, EN-FY1701 Revision A.

Regier R. (2013). “Application of fiber optics on reinforced concrete structures to develop a structural health monitoring technique. Master thesis, Queen's Univ., Kingston, ON, Canada.

Rodríguez G., Casas J.R. and Villalba S. (2014), "Assessing cracking characteristics of concrete structures by distributed optical fiber and non-linear finite element modelling", Proceedings of $7^{\text {th }}$ European Workshop on Structural Health Monitoring, Nantes, France, July.

Rodríguez G., Casas J.R. and Villalba S. (2015a), "Cracking assessment in concrete structures by distributed optical fiber”, Smart Materials and Structures, 24; pp 1-11.

Rodríguez G., Casas J.R. and Villalba S. (2015b), Monitoring flexural and shear cracking pattern in concrete structures by distributed optical fiber, Proceedings of $7^{\text {th }}$ International Conference on Structural Health Monitoring of Intelligent Infrastructure, Torino, Italy, July.

Rodríguez G., Casas J.R. and Villalba S. (2015c) "SHM by DOFS in civil engineering: a review". Structural Monitoring and Maintenance, an International Journal, Vol 2, N.4, pp. 357-382. DOI: 10.12989/smm.2015.2.4.357

Rodríguez G., Casas J.R., Villalba S. and Barrias A. (2016) "Monitoring of shear cracking in partially prestressed concrete beams by distributed optical fiber sensors", Proceedings of $8^{\text {th }}$ International Conference on Bridge Mantenance, Safety and Management, Iguazu, Brazil, June

Rodríguez G. (2017). Monitorización de estructuras de hormigón mediante sensores de fibra óptica distribuida. D Thesis, Technical University of Catalonia, UPC, Barcelona (in Spanish).

Samiec D. (2012), "Distributed fibre-optic tempetature and strain measurement with extremely high spatial resolution", Photonik International, 1, 10-13.

Stoerzel J., and Randal N. (2015) "Monitoring shear induced degradation of reinforced and pretensions concrete members". IABSE Conference. Structural Engineering: Providing Solutions to Glogal Challenges. Geneva, Suiza.

Villalba S. (2010), "Diseño y validación experimental de uniones mediante superposición de lazos de armaduras en viaductos de hormigón de sección transversal evolutiva. Optimización del proceso constructivo", $\mathrm{Ph}$. D Thesis, Technical University of Catalonia, UPC, Barcelona (in Spanish).

Villalba S. and Casas J.R. (2013), “Application of optical fiber distributed sensing to health monitoring of concrete structures", Mechanical Systems and Signal Processing, 39; pp 441-451. 
Zakaria M., Ueda T., Wu Z. and Meng L. (2009). Experimental Investigation on shear cracking behaviour in reinforced concrete beams with shear reinforcement. Journal of Advanced Concrete Technology. Vol. 7 No.1. Japan Concrete Institute, February; pp $79-95$. 